\title{
The fouling phenomenon in membrane bioreactors: Assessment of different strategies for energy saving
}

\author{
Giorgio Mannina*, Alida Cosenza \\ Dipartimento di Ingegneria Civile, Ambientale, Aerospaziale, dei Materiali, Università di Palermo, Viale delle Scienze, 90128 Palermo, Italy
}

\section{A R T I C L E I N F O}

\section{Article history:}

Received 3 March 2013

Received in revised form

21 May 2013

Accepted 22 May 2013

Available online 29 May 2013

\section{Keywords:}

ASM

Energy costs

Integrated MBR model

Membrane fouling

\begin{abstract}
A B S T R A C T
Membrane fouling represents one of the major issues for a membrane bioreactor (MBR). Membrane fouling and high aeration requirements (for inducing shear stress to limit fouling) make MBR operation economically demanding due to high energy costs. Although several studies on MBR fouling have been performed, comprehensive knowledge on how to reduce membrane fouling and consequently save energy is still lacking.

An integrated mathematical model for MBR is applied to a University of Cape Town membrane bioreactor with the final aim to reduce the energy costs. In particular, the influence of the aeration intensity, the duration of filtration/backwashing cycles, and the number of membrane cleanings are investigated. Five scenarios are analyzed and compared, each implementing different operating conditions. The features of the analyzed scenarios are quantified by employing Monte Carlo simulations and performance indices partially drawn from literature. The results provide insights about the role played by the main physical/chemical/biological processes in view of a system optimization. As expected, MBR operation at low air flow rate (qa) leads to a substantial reduction of the operational costs (specifically, 20\% with respect to the suggested manufacturers ones in terms of qa). Despite such a reduction of qa, a good effluent quality is also obtained as an effect of a high biological cake thickness. Results also show that the values of filtration time (Tf) higher than those suggested by manufacturers (e.g., $\mathrm{Tf}=9 \mathrm{~min}$ ) can be used to increase effluent quality. This study demonstrates that both energy savings and effluent quality can be improved by varying the operational variables with respect to those of the suggested manufacture. One of the main insights gained from this study is that the values of the operating variables (i.e., qa, Tb and Tf) suggested by the manufactures can be changed to obtain a system that still respects high effluent quality and is characterized by lower economical cost. The proposed modeling approach can be an useful tool for the optimization of the operating conditions in order to reduce the operational costs for MBR systems.
\end{abstract}

(c) 2013 Elsevier B.V. All rights reserved.

\section{Introduction}

A Membrane Bioreactor (MBR) is an emerging technology increasingly used for wastewater treatment [1]. Despite the numerous advantages of MBR over the conventional activated sludge (CAS) process (e.g., high effluent quality, reduced footprint, lower excess sludge, higher organic loading rates applicable), the MBR technology is affected by crucial issues that may hamper widespread application. Membrane fouling is certainly one of the major obstacles [2]. More specifically, fouling causes permeability reduction and/or an increase of transmembrane pressure (TMP) leading to significant operating costs. The required energy due to TMP as well as the high aeration requirements, make MBR

\footnotetext{
* Corresponding author. Tel.: +39 091 23896556; fax: +39 0916657749.

E-mail address: giorgio.mannina@unipa.it (G. Mannina).
}

an economically demanding technology. Among the operating conditions, aeration represents a crucial element for membrane fouling. In fact, aeration is used both to provide oxygen for maintaining activated sludge in suspension and to reduce fouling by scouring on the membrane surface [3]. A balance between flux, TMP, energy demand and cleaning frequency is crucial [4,5]. To date, many researchers have been working on membrane fouling in order to identify which factors affect this phenomenon and how to reduce the operating costs [6-8].

The required energy to achieve a pressure suitable for flow reversion (backwashing) or for aeration (relaxation combined with aeration) contributes to increase the MBR energy demand and consequently operating costs [9]. The reduction of operating costs is recommended in order to make MBR technology more competitive and widely applicable.

In the past, due to limit operating costs previous experimental studies have demonstrated how modifying factors that affect 
membrane fouling lead to a possible reduction of MBR operating costs $[10,11]$. Meng et al. [12], by analyzing the behavior of three MBR pilot plant, demonstrated that the increase of aeration rate may also negatively affect membrane fouling. An intense aeration rate may damage the structure of flocs reducing their size, and releasing EPS in the bioreactor thus increasing fouling phenomenon $[13,14]$.

Despite the useful insights gained by previous experimental studies, there are still some gaps in the understanding of the roles played by the overall operating conditions in the definition of the optimal conditions for reducing fouling (i.e., economic costs) and, on the other hand, for optimizing system performances in terms of effluent quality. Experimental studies may present some limits in terms of both economic costs and investigation time requirements. Furthermore, experimental studies may offer only a limited and narrow spectrum of possible alternatives, and consequently not all the possible combinations of operating conditions can be explored. Consequently, comprehensive knowledge is still lacking and many aspects are still controversial [2].

In this context, MBR mathematical models are a useful tool to predict membrane fouling and to select which operating conditions have to be optimized to reduce energy costs (e.g., [15]). MBR models may allow exploring a wide range of operating conditions and comparing different solutions prior to their effective realization/ application. However, studies on a joint simulation of both biological and physical processes for MBR are rare (among others, [16-18]) and research on the evaluation of system performance and energy consumption for MBR are at a somewhat elementary state.

In particular, from the literature three MBR modeling approaches can be pin down [58]: biomass kinetic models, membrane fouling models and integrated models. The kinetic models are based on the activated sludge models (ASMs) which have been properly adapted [29]. In more detail, the ASMs have been modified to take into account the formation and degradation of the soluble microbial products (SMPs) in the MBR [15]. Actually, in the technical literature among the kinetic models, the hybrid models, which are basically a coupling of the ASMs and the SMP formation/degradation process, are also defined. In contrast to the kinetic models, the hybrid models enable describing the influences of SMPs in the biological processes and effluent quality [5]. Regarding the second approach of MBR models, i.e., membrane fouling ones, many mathematical modelling approaches have been considered to simulate the fouling phenomenon so far: some of them are basically straightforwardly based on solids-liquid separation and simulate filtration processes as ideal settler with unitary efficiency [22]. Other models consider specific physical approaches: cross flow filtration and mass transport models [21,22]. Nevertheless, membrane fouling is generally evaluated by employing the resistance-in-series model [58] or, rarely, empirical models [59]. Finally, the integrated models, basically couple the kinetic models with the fouling one (such as the resistance-in-series model) and often consider the formation and degradation of SMP. Among the published integrated models only a few models take into account the relationships between the reversible fouling (i.e., cake layer) and the biological processes (among others, [15-17]). Recently Zuthi et al. [60] addressed the importance of using integrated modeling approach with the use of resistance-in-series models to better simulate the membrane fouling, as physical mechanisms of membrane play a vital role.

In the wastewater treatment plant (WWTP) field several optimization studies have been carried out for the assessment of the best operating conditions obtained by minimizing the operational costs and keeping high plant performances in terms of effluent quality. However, such studies refer mainly to CAS systems (among others, [19-21]). Despite the useful results from previous literature studies, the transferability of the results derived for CAS is limited and cannot be directly referred to MBR which requires dedicated and ad-hoc studies [22]. To overcome such an issue, Maere et al. [23] presented an optimization study for evaluating different MBR control strategies based on an ad-hoc platform. Such platform was realized on the basis of the existing COST/Benchmark Simulation Model No.1 (BSM1) [24,25] widely used as a procedure for designing and evaluating control strategies for CAS systems. By using the proposed platform (BSM-MBR) the authors quantified, for both steady and dynamic conditions, the energy requirement in terms of aeration, pumping and mixing. Despite the useful insights gained from the study [23] there are some criticisms on the results due to the simplified modeling approach. An ideal membrane was assumed and some biological/physical processes deemed to be crucial for MBR (e.g., pore fouling, interaction between biological and physical processes etc.) were not taken into account. Furthermore, phosphorus removal was not taken into account; such a fact is quite common in integrated MBR modeling studies where phosphorus removal is scarcely studied $[5,26,27]$.

The above literature review shows that a comprehensive analysis of interactions among the relevant operating conditions simultaneously considering both biological (including phosphorus removal) and physical processes is lacking so far. Bearing in mind such considerations the main aim of this paper is to provide hints for selecting the best MBR management strategies for energy saving and maintaining high effluent quality. For this purpose, the influence of the aeration intensity, the duration of filtration/ backwashing cycles and the number of membrane cleanings on the MBR energy demand has been investigated. In more detail, the problem statement for the pursue of this study is: how can we select the best operating conditions in terms of aeration and duration of filtration/backwashing for an MBR system by limiting fouling?. To accomplish such goals an integrated MBR model able to account for both biological and physical processes was employed. The integrated MBR model was applied to a University Cape Town (UCT)-MBR pilot plant and calibrated by means of measured data gathered during previous studies [16,28]. Five scenarios were analyzed and compared in terms of energy requirements, effluent quality, and economic costs.

\section{Materials and methods}

\subsection{The MBR model}

The study was performed by using an integrated ASM2d-SMP-P MBR model developed in previous studies [16,17]. The model describes both biological and physical processes that occur in an MBR system and is divided into two sub-models: a biological and a physical sub-model. The MBR model involves 19 biological state variables and 79 parameters (kinetic, stoichiometric, physical and fractionation-related). The biological sub-model simulates the biological processes according to the ASM2d [29] and includes the production/degradation processes of soluble utilization associated products (SUAP) and of soluble biomass associated products (SBAP). More specifically, the biological sub-model includes anaerobic, aerobic and anoxic hydrolysis processes of both UAP and BAP $[16,30]$. Six hydrolysis processes introduce four parameters: the fraction of BAP and UAP generated per biomass decayed (respectively, $f_{B A P}$ and $f_{U A P}$ ) and the hydrolysis rate coefficient for $S_{B A P}$ and $S_{U A P}$ (respectively, $k_{H, B A P}$ and $k_{H, U A P}$ ).

The stoichiometric, composition and kinetic rates for the reaction processes are expressed according to the classical ASM matrix format [16]. In particular, the biological reaction rate of a component $(i)$, at time $(t), r_{i}$ is derived by means of the equations:

$r_{i}=\sum_{j=1}^{m} \nu_{i, j} \rho_{j}$ 
where $v$ is the stoichiometric matrix, $i$ and $j$ are, respectively, the state variables and the biological processes, $\rho$ is the kinetic rate, and $m$ is the number of process involved.

The physical sub-model simulates the main physical processes that occur in the MBR which are influenced by or may influence the biological sub-model. Specifically, several processes are taken into account [16,17]: cake layer formation during suction and backwashing phases; COD removal throughout cake layer which acts as a filter; COD removal due to physical membrane; pore fouling; pore blocking; and influence of SMP on pore fouling. The membrane is modeled by dividing its surface into $N$ equal fractions (areal sections) according to the sectional approach method [31]. A different shear intensity of the fluid turbulence $(G)$ is considered as a function of the distance from the aeration systems. Such an approach for $G$ simulation, allows also accounting for the non-uniform sludge cake accumulation on the membrane surface. Both reversible and irreversible fouling is modeled. More specifically, irreversible fouling is modeled as the sum of two contributes: pore fouling, which is caused by the deposition of solutes inside the membrane pores, and stable cake fouling which is caused by deposition of particles on the membrane surface not removed by backwashing. The deposition of solutes inside the pore is carefully taken into account, as it can be crucial for assessing SMP concentration inside the MBR tank and eventually the membrane fouling. Reversible fouling is modeled as dynamic cake fouling caused by deposition of particles removed during backwashing phase.

By means of the deep-bed theory, the MBR model simulates the COD profile over the cake layer [32]. In particular, the model assumes that a fraction of particles can be retained inside the cake layer. In this way, a possible reduction of the COD due to the presence of the cake layer (biological filter) is taken into account (see, $[17,33])$. The total filtration resistance $\left(R_{t}\right)$ is calculated as the sum of the total resistances of each $i$ th areal section $\left(R_{t S(i)}\right)$. In particular, $R_{t S(\mathrm{i})}$ is computed as the sum of the intrinsic membrane resistance $\left(R_{m, i}\right)$, the resistance due to the pore fouling $\left(R_{p, i}\right)$ and the resistance due to the cake layer $\left(R_{c, i}\right)$. This latter resistance is considered as the sum of two contributes, one related to the dynamic cake layer $\left(R_{d c, i}\right)$ that represents the reversible resistance $\left(R_{r e v, i}\right)$ and another one related to the stable cake layer $\left(R_{s c, i}\right)$. Consequently the $R_{t}$ is computed as follows [17]:

$R_{t}=\underbrace{\sum_{i=1}^{n} R_{m, i}+\sum_{i=1}^{n} R_{p, i}+\sum_{i=1}^{n} R_{s c, i}+\underbrace{\sum_{i=1}^{n} R_{d c, i}}_{R_{\text {rev }}}}_{R_{\text {irr }}}$

where $n$ is the number of membrane areal sections, and $R_{\text {irr }}$ and $R_{r e v}$ are the irreversible and reversible resistances, respectively.

Both the specific filtration resistances of the stable cake $\left(r_{s c}\right)$ and the specific filtration resistances of the dynamic cake $\left(r_{d c}\right)$ are influenced by the SMP. To take into account such a fact, both $r_{s c}$ and $r_{d c}$ are modeled as suggested by literature (i.e., [34] and [35]), employing the following equation:

$r_{s c}=r_{d c}=\frac{T M P^{p}}{\mu^{2}}\left(a+b\left(1-\exp \left(-c\left(\frac{S_{S M P}}{0.8 M L S S}\right)\right)\right)^{d}\right)$

where $a, b, c$ and $d$ are empirical constants, MLSS represents the mixed liquor concentration inside the MBR tank, $\mu$ is the sludge viscosity, $S_{S M P}$ is the SMP concentration in the MBR tank and TMP is the trans-membrane pressure coefficient. The consequent dependency of $R_{t}$ on $S_{S M P}$ has peculiar interest when the aim of modeler is to quantify the energy demand related to the membrane fouling.

Finally, once $R_{t}$ is calculated, the model allows to the determination of TMP as follows:

$T M P=\mu \times j_{t} \times R_{t}$ where $j_{t}$ is the overall flux coefficient. The TMP value has peculiar interest for quantifying the energy demand. The model as well as all the algorithms are coded in Fortran 95. Further details about the MBR model can be found in the literature $[16,17]$.

\subsection{The case study}

Analysis is conducted for a pilot plant with an UCT-MBR scheme, which was operated at a feed inflow of $40 \mathrm{~L} / \mathrm{h}$ of municipal wastewater over 165 days. More specifically, the pilot plant is composed of an anaerobic reactor (average volume of $72 \mathrm{~L}$ ), an anoxic reactor (average volume of $165 \mathrm{~L}$ ), an aerobic reactor (average volume of $327 \mathrm{~L}$ ), and an additional aerobic tank (average volume of $52 \mathrm{~L}$ ) in which two hollow fibre membrane modules were submerged (both membrane type Zenon Zeeweed 10 (ZW10); nominal pore size, $0.04 \mu \mathrm{m}$; total membrane area, $\left.1.86 \mathrm{~m}^{2}\right)$. The two membranes have been located in a separate tank in order to better single out the two air flow goals: oxygen transfer for biological processes and air scouring on membrane surface for limiting the solids deposition. The plant was fed with a constant flow of $40 \mathrm{~L} \mathrm{~h}^{-1}$ (constant flux strategy). Until day 76 it was operated with complete sludge retention, while after day 76 the sludge was regularly withdrawn, maintaining the sludge age near to 37 days. During the entire experimental period the following samples were obtained: composite influent wastewater samples (Section 0), grab mixed liquor samples in each tank (i.e., anaerobic, anoxic, aerobic and MBR tank, respectively, Sections 1-4), mixed liquor samples in the oxygen depletion reactor (Section 6) and in the permeate (Section 5). This was done three times per week and the samples were analysed for total and volatile suspended solids (TSS and VSS), total and soluble $\mathrm{COD}, \mathrm{NH}_{4}-\mathrm{N}, \mathrm{NO}_{2}-\mathrm{N}, \mathrm{NO}_{3}-\mathrm{N}, N_{\text {TOT }}$, $P_{\text {Tот }}[36]$. Data acquired during the sampling campaign were used in a previous study for the model parameters calibration by employing an innovative calibration protocol [16,47]. Further details about the pilot plant and sampling campaign can be found in Cosenza et al. [28] and Di Trapani et al. [37].

\subsection{Evaluation criteria}

For the evaluation criteria of the UCT-MBR, two indices have been adopted: the effluent quality index (EQI) and the operational costs (OC). The latter was calculated as a function of the power energy requirement (permeate extraction and aeration), the chemical consumption for membrane cleanings and the effluent fines.

\subsubsection{The effluent quality index}

The EQI, expressed in $\mathrm{kg}$ pollution units per day $\left[\mathrm{kg} \mathrm{PU} \mathrm{d}^{-1}\right]$, is calculated as the weighed sum of the pollutants mass discharged over the entire evaluation period $(T)$ [38]:

$$
\begin{aligned}
\mathrm{EQI}= & \frac{1}{T \times 1000} \int_{t_{0}}^{t_{1}}\left(\beta_{\mathrm{COD}} \times \mathrm{COD}_{e}(t)+\beta_{\mathrm{NH}} \times S_{\mathrm{NHe}}(t)+\beta_{\mathrm{NO}} \times S_{\mathrm{NO} e}(t)\right. \\
& \left.+\beta_{\mathrm{PO}} \times S_{\mathrm{POe}}(t)\right) \times Q_{e f f}(t) d t
\end{aligned}
$$

where $\beta_{C O D}, \beta_{N H}, \beta_{N O}$ and $\beta_{P O}$ are, respectively, the weighting factors of the effluent concentration of $\operatorname{COD}\left(\operatorname{COD}_{e}(t)\right)$, ammonia $\left(S_{\mathrm{NHe}}(t)\right)$, nitrate $\left(S_{\mathrm{NOe}}(t)\right)$ and orthophosphate $\left(S_{\mathrm{POe}}(t)\right)$. The $\beta_{i}$ factors allow conversion of the discharged mass of each effluent component (e.g., $C O D_{e} \cdot Q_{e f f}$ ) into pollution units. In particular, the $\beta_{i}$ factors were determined based, in part, on empirical effluent component weightings. These weightings are based on a study employing a Flanders effluent quality formula for calculating fines [40]. Using the steady state data for each of the layouts it is possible to calculate the organic and nutrient terms based on the Flanders equation [24]. According to Copp [40], from these terms it is then possible to determine the specific fraction that each term 
comprises of the fine formula i.e., \%nutrients $=N_{\text {nutrients }} /$ $\left(N_{\text {nutrients }}+N_{\text {organics }}\right)$. The $\beta_{i}$ factors were chosen to reflect these calculated fractions [24]. Moreover, similarly to previous studies (i.e., $[61,62])$ for better agreement with ecological aspects related to nutrients discharge the highest weighting factor was considered for phosphorus. In this study the following weighting factors were employed [23,38]: $\beta_{\mathrm{COD}}=1, \beta_{\mathrm{NH}}=20, \beta_{\mathrm{NO}}=20$ and $\beta_{\mathrm{OP}}=50$.

The contribution of $\mathrm{COD}_{e}(t), S_{\mathrm{NH} e}(t), S_{\mathrm{NOe}}(t)$ and $S_{\mathrm{POe}}(t)$ to the EQI value is defined as $\mathrm{EQI}_{\mathrm{COD}}, \mathrm{EQI}_{\mathrm{SNH}}, \mathrm{EQI}_{\mathrm{SNO}}$ and $\mathrm{EQI}_{\mathrm{SPO}}$, respectively.

\subsubsection{The operational costs}

In order to evaluate the operational costs, similarly to previous studies three contributions are considered $[21,39,40]$ : costs due to the energy demand for aeration and permeate extraction, costs due to the chemical consumption for membrane cleanings and costs due to effluent fines applied to the EQI. The operational costs were calculated by adapting the cost function proposed by Vanrolleghem and Gillot [39] for the case of MBR systems. More specifically, OC has been computed as:

$O C=\left(P_{w}+P_{e f f}\right) \times \gamma_{e}+C C+E F$

where $O C\left[€ \mathrm{~m}^{-3}\right]$ is the total operational cost, $P_{w}$ and $P_{\text {eff }}$ are the required energy per $\mathrm{m}^{3}$ of permeate extracted, respectively, for aeration and permeate extraction $\left[\mathrm{kW} \mathrm{h} \mathrm{m}^{-3}\right], \gamma_{e}\left[€ \mathrm{~kW} \mathrm{~h}^{-1}\right]$ represents the cost of $1 \mathrm{~kW} \mathrm{~h}, C C\left[€ \mathrm{~m}^{-3}\right]$ represents the cost related to the chemicals consumption required for the membrane cleanings, and $E F\left[€ \mathrm{~m}^{-3}\right.$ ] represents the effluent fines. Regarding CC, a typical membrane cleaning protocol was assumed for calculating chemical consumption $[1,41]$. Such a protocol takes into account the cleaning with a solution of $500 \mathrm{ppm}$ of $\mathrm{NaOCl}$ and $2000 \mathrm{ppm}$ of citric acid. The chemical product prices indicated by Brepols [41] were considered for citric acid $50 \%$ and $\mathrm{NaOCl} 14 \%$, respectively, $760 €$ ton $^{-1}$ and $254 € \mathrm{~m}^{-3}$. Finally, for the energy costs a value of $0.0806 € \mathrm{~kW} \mathrm{~h}^{-1}$ is considered according to the Italian fare.

2.3.2.1. Aeration and pumping permeate energy. The computed aeration energy demand considers the power requirement in the case of adiabatic compression according to the following expression [42]:

$P_{w, p}=\frac{w R T}{29.7(0.283) e}\left[\left(\frac{p_{2}}{p_{1}}\right)^{0.283}-1\right]$

where $P_{w, p}[\mathrm{~kW}]$ is the power requirement for each blower, $w$ is the mass flow of air $\left[\mathrm{kg} \mathrm{s}^{-1}\right], R$ is the gas constant for air $[8.314 \mathrm{~kJ}$ $\mathrm{kmol}^{-1} \mathrm{~K}^{-1}$ ], $T$ is the absolute temperature [K], $p_{1}$ and $p_{2}$ are the absolute inlet and outlet pressure [atm], respectively, 29.7 is a constant according to the International system of units, 0.283 is a constant for air, $e$ is the blower efficiency (common range 0.7-0.9).

The energy requirement for pumping permeate flow $\left(Q_{e f f}\right)$ is evaluated by using the expression suggested by Judd and Judd [1]:

$P_{e f f, p}=\frac{1}{t_{1}-t_{0}} \int_{t_{0}}^{t_{1}} \frac{T M P Q_{e f f}(t)}{3600 \eta} d t$

where $P_{\text {eff,p }}[\mathrm{kW}]$ is the permeate pumping power requirement, TMP $[\mathrm{kPa}]$ is the trans-membrane pressure, $Q_{\text {eff }}\left[\mathrm{m}^{3} \mathrm{~h}^{-1}\right]$ is the effluent flow rate, $t_{0}$ and $t$ are, respectively, the initial and the final time of pump operation, and $\eta$ is the permeate pump efficiency. The same expression [7] has been used to evaluate the energy requirement for backwashing.

2.3.2.2. Effluent fines. The EFs are calculated by comparing the quality of $n$ effluent pollutants $(j)$ with the effluent limits [40]:

$E F=\frac{1}{t_{2}-t_{1}} \times \int_{t_{1}}^{t_{2}}\left[\frac{1}{Q_{I N}} \times\left(\sum_{j=1}^{n}\left(Q_{e f f}(t) \times \Delta \alpha_{j} \times C_{j}^{E F F}(t)+\left(Q_{e f f}(t)\right)\right.\right.\right.$

$$
\begin{aligned}
& \left.\times\left[\beta_{0, j}+\left(C_{j}^{E F F}(t)-C_{L, j}\right) \times\left(\Delta \beta_{j}-\Delta \alpha_{j}\right)\right]\right) \\
& \left.\left.\times\left(\text { Heaviside } \times\left(C_{j}^{E F F}(t)-C_{L, j}\right)\right)\right)\right] \times d t
\end{aligned}
$$

where $t_{2}-t_{1}$ represents the entire evaluation period $(T), Q_{I N}$ and $Q_{\text {eff }}(t)$ represent the influent and effluent flows respectively, $C_{j}^{E F F}$ and $C_{L, j}$ are the concentrations and effluent limit of the pollutant " $j$ ", $\Delta \alpha_{j}$ represents the slope of the curve EF versus $C_{j}^{E F F}$ when $C_{j}^{E F F}<C_{L, j}$, $\Delta \beta_{j}$ represents the slope of the curve EF versus $C_{j}^{E F F}$ when $C_{j}^{E F F}>C_{L, j}$, $\beta_{0, j}$ is the increment of fine in case $C_{j}^{E F F}>C_{L, j}$. The Heaviside function is equal to 1 when $C_{j}^{E F F}>C_{L, j}$ and equal to 0 when $C_{j}^{E F F}<C_{L, j}$.

For the case under study the concentrations of total COD $\left(\mathrm{COD}_{\mathrm{TOT}}\right)$, ammonium $\left(S_{\mathrm{NH}}\right)$, nitrate $\left(S_{\mathrm{NO}}\right)$ and phosphate $\left(S_{\mathrm{PO}}\right)$ in the permeate are taken into account as pollutants.

Table 1 summarizes the values of the parameters used, in the case under study, for the EF computation. The value of $\mathrm{Ci}, \mathrm{L}$ was established according to the emission limits suggested by Italian laws. For $\mathrm{COD}_{\mathrm{TOT}}, S_{\mathrm{NH}}$ and $S_{\mathrm{PO}}$ the same values of the parameters $\Delta \alpha_{\mathrm{j}} \Delta \beta_{\mathrm{j}}$ and $\beta_{0 \mathrm{j}}$, used by Stare et al. [43] for the effluent ammonia were used. Conversely for $S_{\mathrm{NO}_{3}}$ the values used by Stare et al. [43] for the total nitrogen were considered.

\subsection{The investigated scenarios}

The influence of the aeration intensity in the MBR tank, the duration of filtration/backwashing cycles, and the number of membrane cleanings is analyzed by means of the integrated MBR model via Monte Carlo simulations and considering five scenarios.

The contribution of the air flow for providing oxygen to the aerobic reactor (third tank) has been singled out from the contribution of the fouling reduction by scouring on the membrane surface. The air flow due to the aeration of the aerobic reactor (third tank) has been kept constant in the five simulated scenarios. Furthermore, the oxygen concentration in the aerobic reactor has been modeled by considering the classical modelling approach for the ASMs [29]. To better single out the aeration contribution for providing oxygen from those for reducing fouling, the membrane has been located in an ad-hoc tank and not in the aerobic reactor as in the classical submerged configuration scheme.

The first scenario (namely, the benchmark scenario) is characterized by the following conditions: (i) pilot plant under the real operating conditions during which the field data gathering campaign was carried out and (ii) model parameters derived by conditioning the MBR model to measured data. The second scenario is in regards to the assessment of the air flow rate (qa). In particular, all model parameters are kept constant (i.e., equal to the benchmark scenario values) except the value of qa inside the MBR tank. The third scenario considers the assessment of the duration of filtration (Tf) and backwashing (Tb) phases. Specifically, the values of $\mathrm{Tf}$ and $\mathrm{Tb}$ are simultaneously changed while keeping the other model parameters to the calibrated values as constant (i.e., the benchmark scenario). The fourth scenario is related to the assessment of the interactions between three

Table 1

Values of the parameters used for the evaluation of effluent fines for each pollutant taken into account.

\begin{tabular}{llllc}
\hline Pollutant & $\Delta \alpha_{j}\left[€ \mathrm{~kg}^{-1}\right]$ & $\Delta \beta_{j}\left[€ \mathrm{~kg}^{-1}\right]$ & $\beta_{0, j}\left[10^{-3} € \mathrm{~m}^{-3}\right]$ & $C_{L, j}\left[\mathrm{mg} \mathrm{L}^{-1}\right]$ \\
\hline COD $_{\mathrm{TOT}}$ & 4 & 12 & 2.7 & 125 \\
$S_{\mathrm{NH}}$ & 4 & 12 & 2.7 & 2 \\
$S_{\mathrm{NO} 3}$ & 2.7 & 8.1 & 1.4 & 13 \\
$S_{\mathrm{PO}}$ & 4 & 12 & 2.7 & 2 \\
\hline
\end{tabular}


operating variables (namely, qa, Tb and Tf). For this purpose for the fourth scenario the values of $\mathrm{qa}, \mathrm{Tb}$ and $\mathrm{Tf}$ are simultaneously changed via Monte Carlo simulations. Finally, regarding the fifth scenario, the interactions between $\mathrm{qa}, \mathrm{Tb}$, and $\mathrm{Tf}$ are analyzed by superimposing a TMP threshold (TMP_TR). Specifically, as soon as the TMP reaches the TMP_TR value, a membrane cleaning is taken into account, thus reducing the operational TMP. Similar to the previous scenarios, qa, Tb and Tf are changed via Monte Carlo simulations and the other model parameters are kept constant. Scenario 5 differs from previous ones where membrane cleanings are superimposed on the basis of real operating conditions (i.e., the benchmark scenario) and without directly taking into account the TMP increase during plant operation. For scenarios 1-4 the number of membrane cleanings is considered the same as the real pilot plant operation (i.e., the benchmark scenario).

\subsubsection{The modeling conditions}

For each scenario, steady-state and dynamic simulations were performed. More specifically, before running the dynamic simulations the MBR model was first run for assessing the steady-state conditions. In particular, for each scenario and set of model parameters, steady-state simulations were performed imposing constant values for the input variables. The duration of the steadystate simulations was three times the sludge age (see [44]) and it was followed by $165 \mathrm{~d}$ of dynamic simulations.

Table 2 summarizes the biokinetic, stochiometric, and physical model parameter values employed. Such values have been derived by a previous study during which model calibration was carried out for the UCT-MBR pilot plant $[17,28,37]$. More specifically, the model parameters were calibrated by employing an innovative calibration protocol [17] based on the combination of the Global Sensitivity Analysis [45] and the Generalized Likelihood Uncertainty Estimation methodology [46].

The dynamic simulations of the ASM2d-SMP-P were performed by using a continuous input series of the following model input variables: total $\operatorname{COD}\left(\mathrm{COD}_{\mathrm{TOT}}\right)$, soluble undegradable organics $\left(\mathrm{S}_{\mathrm{I}}\right)$, fermentable organic matter $\left(S_{\mathrm{F}}\right)$, acetate $\left(S_{\mathrm{A}}\right)$, nitrate $\left(S_{\mathrm{NO} 3}\right)$, ammonia $\left(S_{\mathrm{NH}}\right)$ and orthophosphate $\left(S_{\mathrm{PO}}\right)$. The dynamic input was obtained by means of a Fourier series calibrated on the basis of measured data [47-49]. The main features of influent series are reported in Table 3.

In Table 4 the adopted values for qa, Tb, and Tf are shown. For scenarios 2-5, 1000 Monte Carlo simulations were performed sampling, due to the lack of information (see, [50]), from a uniform distribution function of the parameters with the Latin hypercube sampling method [51] and according to the uncertainty ranges of the model parameters in Table 4 . The number of simulations was calculated similarly to previous studies [52,53]. More specifically, simulations were performed step by step considering an increasing number of sampled variables. At each step, the distributions of each model variable were compared to those obtained in the previous step. The number of simulations adopted for each was reached when the differences between the results of the two steps were not appreciable according to the Kolmogorov-Smirnov maximum distance test with a significance level of 0.01 .

For the benchmark scenario qa, Tf and Tb were not varied and their values were kept constant according to the manufacturer value shown in Table 4. Conversely, for scenario 5 a TMP_TR value equal to $45 \mathrm{kPa}$ was chosen according to manufacturer suggested values.

\section{Results and discussion}

\subsection{Results of the benchmark scenario}

In Fig. 1 the average cake layer thickness and model resistances (reversible and irreversible) are given. Both resistances and cake layer thickness show a temporal "saw tooth" profile indicating phases of solids deposition on the membrane surface and solid erosion. In particular, the eight "teeth" of Fig. 1 are the effect of the MBR cleanings carried out during plant operation. $R_{\text {rev }}$ shows a more narrow "saw tooth" profile than $R_{i r r}$ as an effect of backwashing (one every $9 \mathrm{~min}$ ). $R_{\text {irr }}$ shows an increasing trend as an effect of pore fouling which is consistent with the simulated processes. The maximum value of $R_{\text {irr }}\left(4.02 \times 10^{12} \mathrm{~m}^{-1}\right)$ occurs at the 83 rd day (Fig. 1a). The value of $R_{\text {rev }}$ is approximately stable during the entire simulation period and is characterized by an average value of $0.147 \times 10^{12} \mathrm{~m}^{-1}$ (Fig. 1a). $R_{\text {irr }}$ provides the highest contribution to $R_{t}$ with an average value of $89 \%\left(R_{i r r} / R_{t}\right)$. Such a result is in agreement with the findings of other researchers. Both Arabi and Nakhla [54] and Sarioglu et al. [55] have found that for an MBR system aimed at the simultaneous nitrification and denitrification, the resistances of pore fouling and intrinsic membrane were the major components of the total resistance. The trends of $R_{i r r}$ and $R_{r e v}$ are strongly connected to the total cake layer thickness reported in Fig. 1b. The average values of the cake layer thickness along the membrane height (Fig. 1b) range between 0 and $0.85 \mathrm{~mm}$ with a mean value equal to $0.27 \mathrm{~mm}$ and is in good agreement with previous studies (among others, [31,56]). Fig. 2 shows the influence of the non-uniform distribution of the shear intensity of the fluid turbulence on the membrane surface for the cake thickness along the membrane height during the filtration period. Specifically, in Fig. 2a the cake layer thickness at the 58th day of plant operation is shown. Fig. 2b shows the cake layer thickness along the membrane height during the last filtration period just before the membrane cleaning on the 84th day. For such a case, the cake thickness thus represents the irreversible cake fraction accumulated from 58th to 84th day.

A total money demand equal to $0.177 € \mathrm{~m}^{-3}$ has been obtained for this scenario. The required energy in terms of aeration and permeate pumping per $\mathrm{m}^{3}$ of produced permeate is respectively equal to $0.5 \mathrm{~kW} \mathrm{~h} \mathrm{~m}^{-3}$ and $0.7 \times 10^{-3} \mathrm{~kW} \mathrm{~h} \mathrm{~m}^{-3}$. This result confirms previous findings which identify the coarse bubble aeration for membrane cleaning as the main MBR energy consumer $[22,23,57]$. The derived value for aeration energy is in line with previous studies [23,56]. Values of 0.59 and $0.53 \mathrm{~kW} \mathrm{~h} \mathrm{~m}^{-3}$ were derived by Suh et al. [56] and Maere et al. [23], respectively. As pointed out by Maere et al. [23], the values are higher with respect to the measured ones for full scale plants which range between 0.23 and $0.45 \mathrm{~kW} \mathrm{~h} \mathrm{~m}^{-3}$. This fact is mainly due to the operation of the membrane aeration. For full scale plants, membrane aeration discontinues differently to the simulated plant where membrane is constantly aerated. Consequently, the obtained value of aeration energy is higher than the measured ones for full scale plants. The low value obtained for permeate pumping energy is mainly due to the modest value of TMP during the overall simulation period. During plant operation, the MBR cleanings were carried out with an high frequency leading to an average TMP value over the overall MBR operation equal to $17 \mathrm{kPa}$.

\subsection{Results of scenario 2}

Figs. 3 and 4 show results related to scenario 2 where only the aeration flow was changed, keeping all the other operating variables constant. In Fig. 3a the effect of aeration on the energy requirement is shown. In Fig. $3 a$ and according to Eq. (7), $P_{w}$ and qa are related by a linear relationship. Conversely, the permeate pumping energy requirement is characterized by a decreasing trend. The greatest power requirement is due to the blowers and, such a power requirement is four orders of magnitude higher than the pumping one. The lowest value of the permeate pumping energy requirement $\left(4.3 \times 10^{-4} \mathrm{~kW} \mathrm{~h} \mathrm{~m}^{-3}\right)$ is obtained for a qa value equal to $14.96 \mathrm{~L} \mathrm{~m}^{-2} \mathrm{~s}^{-1}$ (Fig. 3a), while the lowest value of 
Table 2

Description, symbol, unit and calibrated value for each model parameter ([17]; [13]).

\begin{tabular}{|c|c|c|c|}
\hline Description & Symbol & Unit & Calibrated \\
\hline Maximum specific hydrolysis rate & $k_{H}$ & $\mathrm{~g} X_{\mathrm{S}} \mathrm{g} X_{\mathrm{H}}^{-1} \mathrm{~d}^{-1}$ & 1.72 \\
\hline Correction factor for hydrolysis under anoxic conditions & $\eta_{\mathrm{NO}, \mathrm{HYD}}$ & - & 0.60 \\
\hline Correction factor for hydrolysis under anaerobic conditions & $\eta_{\mathrm{FE}}$ & - & 0.48 \\
\hline Half saturation parameter for $S_{\mathrm{O} 2}$ for $X_{\mathrm{H}}$ & $K_{\mathrm{O}}$ & $\mathrm{g} S_{\mathrm{O} 2} \mathrm{~m}^{-3}$ & 0.54 \\
\hline Half saturation parameter for $\mathrm{S}_{\mathrm{NO} 3}$ for $X_{\mathrm{H}}$ & $K_{\mathrm{NO} 3}$ & $\mathrm{~g} S_{\mathrm{NO} 3} \mathrm{~m}^{-3}$ & 0.32 \\
\hline Half saturation parameter for $X_{\mathrm{S}} / X_{\mathrm{H}}$ & $K_{X}$ & $\mathrm{~g} X_{\mathrm{S}} \cdot \mathrm{g} X_{\mathrm{H}}^{-1}$ & 0.10 \\
\hline Half saturation/inhibition parameter for $S_{\mathrm{O} 2}$ & $K_{\mathrm{O}, \mathrm{HYD}}$ & $\mathrm{g} S_{\mathrm{O} 2} \mathrm{~m}^{-3}$ & 0.20 \\
\hline Half saturation/inhibition parameter for $S_{\mathrm{NO} 3}$ & $K_{\mathrm{NO} 3, \mathrm{HYD}}$ & $\mathrm{g} N \mathrm{~m}^{-3}$ & 0.50 \\
\hline Maximum growth rate of $X_{\mathrm{H}}$ & $\mu_{\mathrm{H}}$ & $\mathrm{d}^{-1}$ & 1.30 \\
\hline Rate constant for fermentation/ Maximum specific fermentation growth rate & $q_{\mathrm{FE}}$ & $\mathrm{g} S_{\mathrm{F}} \mathrm{g} X_{\mathrm{H}}^{-1} \mathrm{~d}^{-1}$ & 3.00 \\
\hline Reduction factor for anoxic growth of $X_{\mathrm{H}}$ & $\eta_{\mathrm{NO}, \mathrm{H}}$ & - & 0.99 \\
\hline Decay rate for $X_{\mathrm{H}}$ & $b_{\mathrm{H}}$ & $\mathrm{d}^{-1}$ & 0.58 \\
\hline Half saturation parameter for $S_{\mathrm{F}}$ & $K_{\mathrm{F}}$ & $\mathrm{g} S_{\mathrm{F}} \mathrm{m}^{13}$ & 4.00 \\
\hline Half saturation parameter for fermentation of $S_{\mathrm{F}}$ & $K_{\mathrm{FE}}$ & $\mathrm{g} S_{\mathrm{F}} \mathrm{m}^{13}$ & 4.00 \\
\hline Half saturation parameter for $S_{\mathrm{A}}$ & $K_{\mathrm{A}}$ & $\mathrm{g} S_{\mathrm{A}} \mathrm{m}^{-3}$ & 4.00 \\
\hline Half saturation parameter for $S_{\mathrm{NH} 4}$ for $X_{\mathrm{H}}$ & $K_{\mathrm{NH}, \mathrm{H}}$ & $\mathrm{g} S_{\mathrm{NH} 4} \mathrm{~m}^{13}$ & 0.10 \\
\hline Half saturation parameter for $S_{\mathrm{PO} 4}$ for $X_{\mathrm{H}}$ & $K_{\mathrm{P}}$ & $\mathrm{g} \mathrm{S}_{\mathrm{PO} 4} \mathrm{~m}^{-3}$ & 0.01 \\
\hline Half saturation parameter for $S_{\mathrm{ALK}}$ for $X_{\mathrm{H}}$ & $K_{\mathrm{ALK}, \mathrm{H}}$ & $\mathrm{mol} \mathrm{HCO}_{3}{ }^{-} \mathrm{m}^{-3}$ & 0.10 \\
\hline Rate constant for $S_{\mathrm{A}}$ uptake rate & $q_{\mathrm{PHA}}$ & $\mathrm{g} X_{\mathrm{PHA}} \mathrm{g} X_{\mathrm{PAO}}^{-1} \mathrm{~d}^{-1}$ & 3.70 \\
\hline Rate constant for storage of polyphosphates & $q_{\mathrm{PP}}$ & $\mathrm{g} X_{\mathrm{PP}} \mathrm{g} X_{\mathrm{PAO}}^{-1} \mathrm{~d}^{-1}$ & 2.34 \\
\hline Maximum growth rate of $X_{\mathrm{PAO}}$ & $\mu_{\text {PAO }}$ & $d^{-1}$ & 0.72 \\
\hline Reduction factor for anoxic growth of $X_{\mathrm{PAO}}$ & $\eta_{\mathrm{NO} 3, \mathrm{PAO}}$ & - & 0.60 \\
\hline Endogenous respiration rate of $X_{\mathrm{PAO}}$ & $b_{\text {PAO }}$ & $d^{-1}$ & 0.24 \\
\hline Rate constant for Lysis of polyphospates & $b_{\mathrm{PP}}$ & $d^{-1}$ & 0.20 \\
\hline Rate constant for respiration of $X_{\mathrm{PHA}}$ & $b_{\mathrm{PHA}}$ & $d^{-1}$ & 0.20 \\
\hline Half saturation parameter for $S_{\mathrm{PO} 4}$ uptake & $K_{\mathrm{PS}}$ & $\mathrm{g} S_{\mathrm{PO} 4} \mathrm{~m}^{-3}$ & 0.20 \\
\hline Maximum ratio of $X_{\mathrm{PP}} / X_{\mathrm{PAO}}$ & $K_{\mathrm{PP}}$ & $\mathrm{g} X_{\mathrm{PP}} \mathrm{g} X_{\mathrm{PAO}}^{-1}$ & 0.01 \\
\hline Half saturation parameter for $X_{\mathrm{PP}} / X_{\mathrm{PAO}}$ & $K_{\mathrm{MAX}}$ & $\mathrm{g} X_{\mathrm{PP}} \mathrm{g} X_{\mathrm{PAO}}^{-1}$ & 0.34 \\
\hline Half inhibition parameter for $X_{\mathrm{PP}} / X_{\mathrm{PAO}}$ & $K_{\mathrm{IPP}}$ & $\mathrm{g} X_{\mathrm{PP}} \mathrm{g} X_{\mathrm{PAO}}{ }^{-1}$ & 0.02 \\
\hline Saturation constant for $X_{\mathrm{PHA}} / X_{\mathrm{PAO}}$ & $K_{\mathrm{PHA}}$ & $\mathrm{g} X_{\mathrm{PHA}} \mathrm{g} X_{\mathrm{PAO}}{ }^{-1}$ & 0.01 \\
\hline Half saturation parameter for $S_{\mathrm{O} 2}$ for $X_{\mathrm{PAO}}$ & $K_{\mathrm{O}, \mathrm{PAO}}$ & $\mathrm{g} \mathrm{S}_{\mathrm{O} 2} \mathrm{~m}^{-3}$ & 0.20 \\
\hline Half saturation parameter for $S_{\mathrm{NO} 3}$ for $X_{\mathrm{PAO}}$ & $K_{\mathrm{NO} 3, \mathrm{PAO}}$ & $\mathrm{g} S_{\mathrm{NO} 3} \mathrm{~m}^{-3}$ & 0.50 \\
\hline Half saturation parameter for $S_{\mathrm{A}}$ for $X_{\mathrm{PAO}}$ & $K_{\mathrm{A}, \mathrm{PAO}}$ & $\mathrm{g} S_{\mathrm{A}} \mathrm{m}^{-3}$ & 4.00 \\
\hline Half saturation parameter for $S_{\mathrm{NH} 4}$ for $X_{\mathrm{PAO}}$ & $K_{\mathrm{NH}, \mathrm{PAO}}$ & $\mathrm{g} \mathrm{S}_{\mathrm{NH} 4} \mathrm{~m}^{-3}$ & 0.05 \\
\hline Half saturation parameter for $S_{\mathrm{PO} 4}$ as nutrient ( $X_{\mathrm{PAO}}$ growth) & $K_{\mathrm{P}, \mathrm{PAO}}$ & $\mathrm{g} S_{\mathrm{PO} 4} \mathrm{~m}^{-3}$ & 0.01 \\
\hline Half saturation parameter for $S_{\mathrm{ALK}}$ for $X_{\mathrm{PAO}}$ & $K_{\mathrm{ALK}, \mathrm{PAO}}$ & $\mathrm{mol} \mathrm{HCO}_{3}{ }^{-} \cdot \mathrm{m}^{-3}$ & 0.10 \\
\hline Maximum growth rate of $X_{\mathrm{AUT}}$ & $\mu_{\text {AUT }}$ & $\mathrm{d}^{-1}$ & 1.18 \\
\hline Decay rate for $X_{\mathrm{AUT}}$ & $b_{\mathrm{AUT}}$ & $\mathrm{d}^{-1}$ & 0.08 \\
\hline Half saturation parameter for $S_{\mathrm{O} 2}$ for $X_{\mathrm{AUT}}$ & $K_{\mathrm{O}, \mathrm{A}}$ & $\mathrm{g} S_{\mathrm{O} 2} \mathrm{~m}^{-3}$ & 0.50 \\
\hline Half saturation parameter for $S_{\mathrm{NH} 4}$ for $X_{\mathrm{AUT}}$ & $K_{\mathrm{NH}, \mathrm{A}}$ & $\mathrm{g} \mathrm{S}_{\mathrm{NH} 4} \mathrm{~m}^{-3}$ & 1.00 \\
\hline Conversion factor $X_{\mathrm{I}}$ in TSS & $i_{\mathrm{TSS}, \mathrm{XI}}$ & g TSS g $X_{\mathrm{I}}^{-1}$ & 0.79 \\
\hline Conversion factor $X_{\mathrm{S}}$ in TSS & $i_{\mathrm{TSS}, \mathrm{XS}}$ & $\operatorname{g~TSS~} \mathrm{g} \mathrm{X}_{\mathrm{S}}^{-1}$ & 0.79 \\
\hline Conversion factor biomass in TSS & $i_{\mathrm{TSS}, \mathrm{BM}}$ & $\mathrm{g}$ TSS $\mathrm{g} X_{\mathrm{BM}}{ }^{-1}$ & 0.95 \\
\hline Conversion factor $X_{\mathrm{PHA}}$ in TSS & $\mathrm{i}_{\mathrm{TSS}, \mathrm{XPHA}}$ & $\operatorname{g~TSS~g~} X_{\mathrm{PHA}}^{-1}$ & 0.60 \\
\hline Conversion factor $X_{\mathrm{PP}}$ in TSS & $\mathrm{i}_{\mathrm{TSS}, \mathrm{XPP}}$ & $\mathrm{g}$ TSS $\mathrm{g}_{\mathrm{PP}}{ }^{-1}$ & 3.23 \\
\hline Half saturation parameter for $S_{\mathrm{ALK}}$ for $X_{\mathrm{AUT}}$ & $K_{\mathrm{ALK}, \mathrm{A}}$ & $\mathrm{mol} \mathrm{HCO}_{3}^{-} \cdot \mathrm{m}^{-3}$ & 0.50 \\
\hline Half saturation parameter for $S_{\mathrm{PO} 4}$ for $X_{\mathrm{PAO}}$ & $K_{\mathrm{P}, \mathrm{A}}$ & $\mathrm{g} S_{\mathrm{PO} 4} \mathrm{~m}^{-3}$ & 0.01 \\
\hline Hydrolysis rate coefficient for $S_{\text {BAP }}$ & $k_{\mathrm{H}, \mathrm{BAP}}$ & $\mathrm{d}^{-1}$ & 7.41E-07 \\
\hline Hydrolysis rate coefficient for $S_{\mathrm{UAP}}$ & $k_{\mathrm{H}, \mathrm{UAP}}$ & $\mathrm{d}^{-1}$ & 0.01 \\
\hline Overall oxygen transfer coefficient aerobic tank & $k_{\mathrm{LaT}, 3}$ & $\mathrm{~h}^{-1}$ & 10.00 \\
\hline Overall oxygen transfer coefficient MBR tank & $k_{\mathrm{LaT}, 4}$ & $\mathrm{~h}^{-1}$ & 3.40 \\
\hline Yield for $X_{H}$ growth & $Y_{\mathrm{H}}$ & $\mathrm{g} X_{\mathrm{H}} \mathrm{g} X_{\mathrm{S}}^{-1}$ & 0.39 \\
\hline Fraction of $X_{\mathrm{I}}$ generated in biomass decay & $f_{X I}$ & $\mathrm{~g} X_{\mathrm{I}} \mathrm{g} X_{\mathrm{H}}^{-1}$ & 0.06 \\
\hline Yield for $X_{\mathrm{PAO}}$ growth & $\mathrm{Y}_{\mathrm{PAO}}$ & $\mathrm{g} X_{\mathrm{PAO}} \mathrm{g} X_{\mathrm{PHA}}{ }^{-1}$ & 0.44 \\
\hline Yield for $X_{\mathrm{PP}}$ requirement per $X_{\mathrm{PHA}}$ stored & $\mathrm{Y}_{\mathrm{PO} 4}$ & & 0.40 \\
\hline Yield for $X_{\mathrm{PP}}$ storage per $X_{\mathrm{PHA}}$ utilized & $\mathrm{Y}_{\mathrm{PHA}}$ & $\mathrm{g} X_{\mathrm{PP}} \mathrm{g} X_{\mathrm{PHA}}^{-1}$ & 0.20 \\
\hline Yield of $X_{\text {AUT }}$ growth per $S_{\mathrm{NO}}$ & $\mathrm{Y}_{\mathrm{A}}$ & $\mathrm{g} X_{\mathrm{AUT} . \mathrm{g} S_{\mathrm{NO} 3}}{ }^{-1}$ & 0.24 \\
\hline Fraction of $S_{\text {BAP }}$ generated in biomass decay & $\mathrm{f}_{\mathrm{BAP}}$ & - & 0.0070 \\
\hline Fraction of $S_{\text {UAP }}$ generated in biomass decay & $\mathrm{f}_{\mathrm{UAP}}$ & - & 0.10 \\
\hline Fraction of influent $S_{\mathrm{F}}$ & $\mathrm{F}_{\mathrm{SF}}$ & - & 0.12 \\
\hline Fraction of influent $S_{\mathrm{A}}$ & $\mathrm{F}_{\mathrm{SA}}$ & - & 0.04 \\
\hline Fraction of influent $S_{\mathrm{I}}$ & $\mathrm{F}_{\mathrm{SI}}$ & - & 0.12 \\
\hline Fraction of influent $X_{\mathrm{I}}$ & $\mathrm{F}_{\mathrm{XI}}$ & - & 0.10 \\
\hline Fraction of influent $X_{\mathrm{H}}$ & $\mathrm{F}_{\mathrm{XH}}$ & - & 0.10 \\
\hline Erosion rate coefficient of the dynamic sludge & $\beta$ & - & 0.01 \\
\hline Stickiness of the biomass particles & $\alpha$ & - & 0.48 \\
\hline Compressibility of cake & $\gamma$ & $\mathrm{kg} \mathrm{m}^{-3} \mathrm{~s}$ & 0.00 \\
\hline Substrate fraction below the critical molecular weight & $\mathrm{f}$ & - & 0.91 \\
\hline Screening parameter & $\lambda$ & $\mathrm{m}^{-1}$ & 1520.29 \\
\hline Efficiency of backwashing & $\mathrm{C}_{\mathrm{E}}$ & - & 0.9960 \\
\hline Empirical constant & $\mathrm{a}$ & - & $1.6510^{5}$ \\
\hline Empirical constant & $\mathrm{b}$ & - & $8.3310^{4}$ \\
\hline Empirical constant & c & - & 253.54 \\
\hline Empirical constant & $\mathrm{d}$ & - & 1427.00 \\
\hline Specific pore fouling resistance & $r_{p}$ & $\mathrm{~m}^{-2}$ & $1.410^{14}$ \\
\hline
\end{tabular}


Table 2 (continued)

\begin{tabular}{|c|c|c|c|}
\hline Description & Symbol & Unit & Calibrated \\
\hline$N$ content of $S_{\mathrm{I}}$ & $\mathrm{i}_{\mathrm{N}, \mathrm{SI}}$ & $\operatorname{g~} N g S_{\mathrm{I}}^{-1}$ & 0.01 \\
\hline$N$ content of $S_{\mathrm{F}}$ & $\mathrm{i}_{\mathrm{N}, \mathrm{SF}}$ & ${\operatorname{g~} N S_{\mathrm{F}}^{-1}}^{-1}$ & 0.03 \\
\hline$N$ content of $X_{\mathrm{I}}$ & $\mathrm{i}_{\mathrm{N}, \mathrm{XI}}$ & $\operatorname{g~} N g X_{I}^{-1}$ & 0.0245 \\
\hline$N$ content of $X_{\mathrm{S}}$ & $\mathrm{i}_{\mathrm{N}, \mathrm{XS}}$ & $\operatorname{g~} N \mathrm{~g} X_{\mathrm{S}}^{-1}$ & 0.0437 \\
\hline$N$ content of biomass & $\mathrm{i}_{\mathrm{N}, \mathrm{BM}}$ & $\operatorname{g~} N g X_{\mathrm{BM}}{ }^{-1}$ & 0.01 \\
\hline$P$ content of $S_{\mathrm{F}}$ & $\mathrm{i}_{\mathrm{P}, \mathrm{SF}}$ & $\mathrm{g} P \mathrm{~g} \mathrm{~S}_{\mathrm{F}}^{-1}$ & 0.03 \\
\hline$P$ content of $X_{I}$ & $\mathrm{i}_{\mathrm{P}, \mathrm{XI}}$ & $\operatorname{g} P \operatorname{g} X_{\mathrm{I}}^{-1}$ & 0.0056 \\
\hline$P$ content of $X_{\mathrm{S}}$ & $\mathrm{i}_{\mathrm{P}, \mathrm{XS}}$ & $\operatorname{g} P \operatorname{g~} X_{\mathrm{S}}^{-1}$ & 0.0099 \\
\hline$P$ content of biomass & $\mathrm{i}_{\mathrm{P}, \mathrm{BM}}$ & $\operatorname{g} P \operatorname{g~} X_{\mathrm{BM}}^{-1}$ & 0.0207 \\
\hline
\end{tabular}

Table 3

Symbol, unit, average, maximum and minimum value of the influent wastewater variables.

\begin{tabular}{llccc}
\hline Variables & Unit & Average & Max & Min \\
\hline COD $_{\text {TOT }}$ & $\mathrm{mg} \mathrm{L}^{-1}$ & 351 & 771 & 81 \\
$S_{\mathrm{I}}$ & $\mathrm{mg} \mathrm{L}^{-1}$ & 42 & 92 & 9.8 \\
$S_{\mathrm{F}}$ & $\mathrm{mg} \mathrm{L}^{-1}$ & 42 & 92 & 9.8 \\
$S_{\mathrm{A}}$ & $\mathrm{mg} \mathrm{L}^{-1}$ & 28 & 62 & 6.5 \\
$X_{\mathrm{I}}$ & $\mathrm{mg} \mathrm{L}^{-1}$ & 35 & 77 & 8 \\
$X_{\mathrm{S}}$ & $\mathrm{mg} \mathrm{L}^{-1}$ & 168 & 370 & 39 \\
$S_{\mathrm{NH}}$ & $\mathrm{mg} \mathrm{L}^{-1}$ & 16 & 38 & 3 \\
$S_{\mathrm{NO} 3}$ & $\mathrm{mg} \mathrm{L}^{-1}$ & 1.3 & 18 & 0.001 \\
$S_{\mathrm{PO}}$ & $\mathrm{mg} \mathrm{L}^{-1}$ & 2.7 & 16.5 & 0.4 \\
\hline
\end{tabular}

Table 4

Description, symbol, unit, manufacturer value and variation range of qa, $\mathrm{Tf}$ and $\mathrm{Tb}$ employed during the scenario analysis.

\begin{tabular}{llllr}
\hline Description & Symbol & Unit & Manufacturer value & Range \\
\hline Air flow rate & qa & $\mathrm{L} \mathrm{m}^{-2} \mathrm{~s}^{-1}$ & 6.67 & $2-15$ \\
Duration of filtration & $\mathrm{Tf}$ & $\mathrm{min}$ & 9 & $5-90$ \\
Duration of backwashing & $\mathrm{Tb}$ & $\mathrm{min}$ & 1 & $0.5-10$ \\
\hline
\end{tabular}

the power requirement for each blower $\left(0.2 \mathrm{~kW} \mathrm{~h} \mathrm{~m}^{-3}\right)$ has obviously been obtained in correspondence to the lowest value of qa (namely, $2 \mathrm{~L} \mathrm{~m}^{-2} \mathrm{~s}^{-1}$ ). The decreasing trend of the permeate pumping energy requirement is mainly due to the TMP reduction (connected to the decrease of $R_{t}$ ) for high qa values. As reported in literature, membrane permeability improves by increasing the aeration intensity [12]. However, the variation of $R_{t}$ due to the qa is mainly attributable to the different role played by $R_{\text {irr }}$ and SMP. The value of qa is higher, and the concentration of SMP inside the membrane tank is lower (Fig. 3b). Consequently, a reduction of $R_{i r r}$ and $P_{\text {eff }}$ takes place. Conversely, for low value of qa, the SMP concentration in the reactor increases (Fig. 3b). This increase of the permeate pumping energy requirement is mainly due to the high SMP retained inside the membrane pores.

The variation of the SMP concentration (Fig. 3b) as an effect of qa is mainly due to the interaction between physical and biological processes. In particular, by reducing qa an increase of the thickness of the cake layer takes place as an effect of the higher amount of solids deposited on the membrane surface. The higher cake layer thickness causes a reduction in the COD concentration at the membrane effluent due to the cake layer basically acting as an extra filter [33]. Such a circumstance leads to an increase of COD inside the MBR tank and consequently the mixed liquor recycled from the MBR to the aerobic tank contains a higher COD mass, thus influencing the biological processes occurring inside the aerobic and the MBR tank. In particular the SMP production process increases due to a higher biomass activity, conversely the higher availability of COD leads to a decrease of SMP degradation.

The money demand showed a linear trend ranging between 0.136 and $0.234 € \mathrm{~m}^{-3}$ for an air flow rate of 2 and $15 \mathrm{~L} \mathrm{~m}^{-2} \mathrm{~s}^{-1}$, respectively. In Fig. $4 \mathrm{a}-\mathrm{d}$ the variation of $\mathrm{EQI}_{\mathrm{COD}}, \mathrm{EQI}_{\mathrm{SNO}}, \mathrm{EQI}_{\mathrm{SNH}}$ and $\mathrm{EQI}_{\mathrm{SPO}}$ versus qa are shown, respectively. By analysing Fig. 4a, EQI $_{C O D}$ increases with qa, and this is mainly due to the variation of cake layer thickness along the membrane surface with varying qa. More specifically, by increasing qa a reduction of the cake layer thickness takes place (Fig. 4f). This is due to the fact that the shear intensity of the fluid turbulence effect on membrane cleaning is higher for a high value of qa (also shown by others, such as Meng et al. [12]). Thus, the cake layer ability to retain particles decreases with increased qa.

By observing Fig. 4b, c one may conclude that increasing qa the variation of nitrification capacity is negligible. Only a slight variation of $\mathrm{EQI}_{\mathrm{SNH}}$ and $\mathrm{EQI}_{\mathrm{SNO}}$ occurs (Fig. 4c, b, respectively). Such a result is mainly due to the good biomass ability of nitrifying in the aerobic tank. Again, the influence of qa on MBR phosphorus uptake can also be considered negligible (Fig. 4d). The aerobic growth of phosphorus accumulating organisms and aerobic phosphorus uptake are mainly regulated by the poly- $\beta$-hydroxylalkanoates stored during the anaerobic phase.

As shown in Fig. 4e, EQI increases globally with qa mainly as an effect $\mathrm{EQI}_{\mathrm{COD}}$ and $\mathrm{EQI}_{\mathrm{SPO}}$ variation.

Fig. $4 \mathrm{~g}$ shows the irreversible resistance $\left(R_{i r r}\right)$ for qa values equal to 2,5 and $15 \mathrm{~L} \mathrm{~m}^{-2} \mathrm{~s}^{-1}$. As reported in Fig. $4 \mathrm{~g}, R_{i r r}$ increases with the decrease of qa. Such a result is mainly due to the higher SMP concentration inside the MBR tank at low qa value as discussed above (Fig. 3b). This demonstrates that a strong relationship exists among qa, SMP production and irreversible membrane fouling highlighting the need for an integrated modelling approach. However, the $R_{i r r}$ at low qa has a lower influence on money demand with respect to qa. Thus lower air flow has a beneficial effect in terms of effluent quality due to the formation of a thicker cake layer that acts as an additional filter (among others, [33]).

For scenario 2 the best condition in terms of energy demand, money demand and EQI corresponds to the minimum value of qa (namely, $2 \mathrm{~L} \mathrm{~m}^{-2} \mathrm{~s}^{-1}$ ). Such a result is consistent with other studies. Suh et al. [56] studied the influence of coarse bubble aeration intensity on membrane fouling and found that the operating conditions with continuous strong membrane aeration are inefficient in terms of energy saving.

\subsection{Results of scenario 3}

In Fig. 5 the results related to the variation of both $\mathrm{Tf}$ and $\mathrm{Tb}$ are shown. It is worth mentioning that $\mathrm{Tf}$ and $\mathrm{Tb}$ were varied independently assuming an uniform distribution according to the variation ranges reported in Table 4 and imposing the condition that $\mathrm{Tf}>\mathrm{Tb}$. Conversely, $T_{\text {cycle }}$ was derived as the sum of $\mathrm{Tf}$ and $\mathrm{Tb}$. In Fig. 5a, the effect of the $T_{\text {cycle }}$ variation on the permeate 

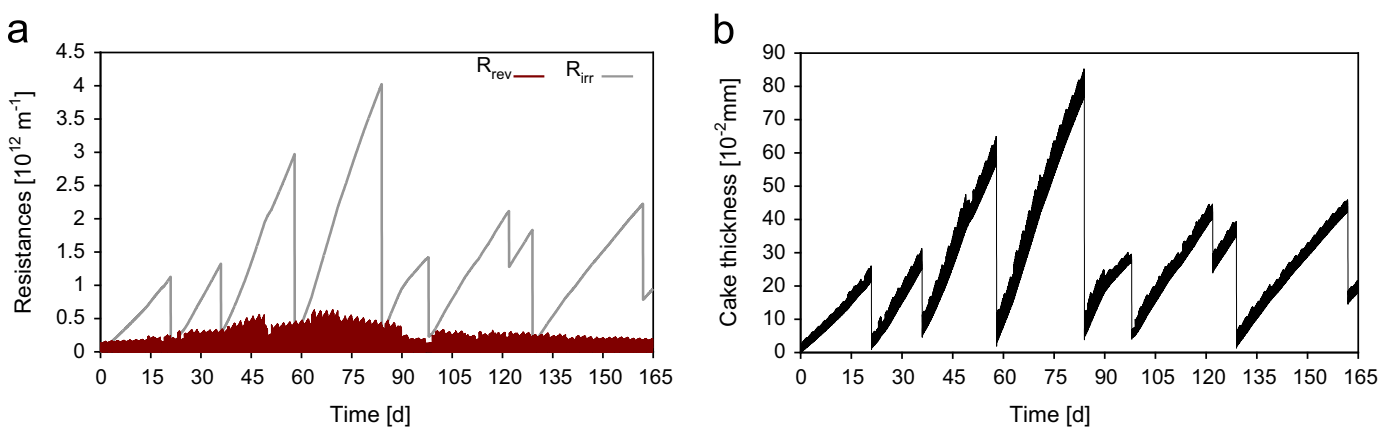

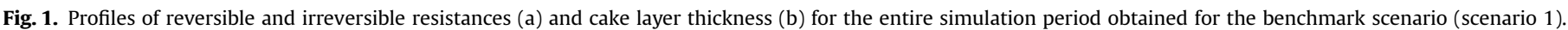

a

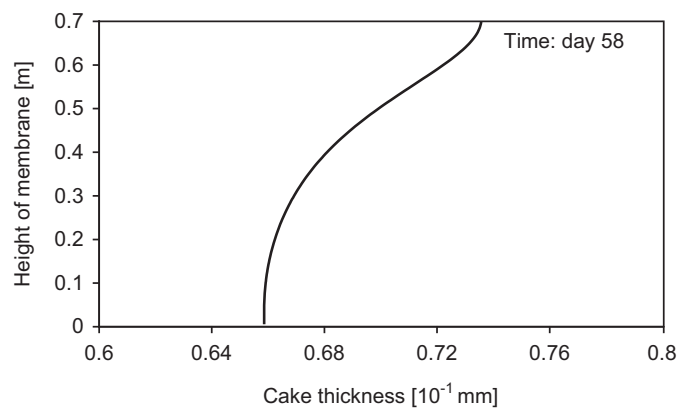

b

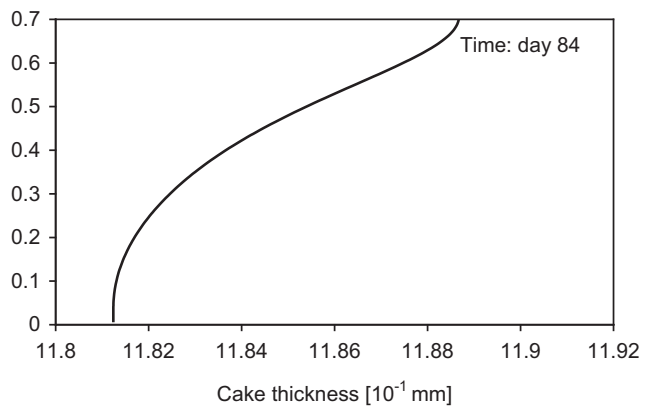

Fig. 2. Thickness of the irreversible cake deposited on the membrane surface along the membrane height at the 58th $d$ (a) and at the 84 th $d$ (b) (scenario 1 ).

a

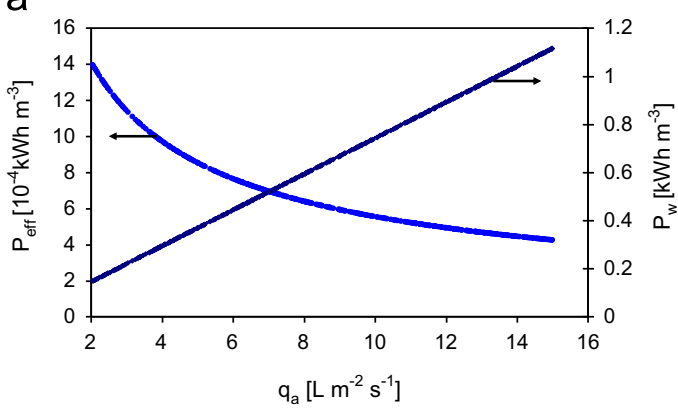

b

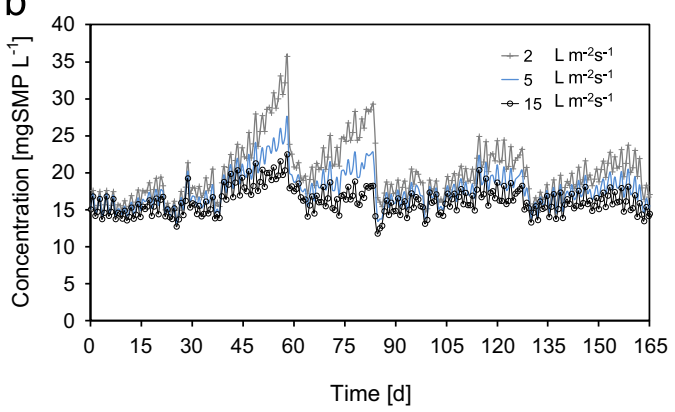

Fig. 3. Variation of $P_{\text {eff }}$ and $P_{w}$ per produced permeate volume vs qa (a) obtained analysing scenario 2; SMP concentration profiles inside the membrane tank for an air flow value of 2,5 and $15 \mathrm{~L} \mathrm{~m}^{-2} \mathrm{~s}^{-1}$ (b) (scenario 2$)$.

pumping energy requirement is shown. Specifically, each dot represents one Monte Carlo run and is basically the sum of two values, i.e., Tf and Tb. Notably, $P_{\text {eff }}$ vs $T_{\text {cycle }}$ is characterized mainly by two different limbs: a decreasing and an increasing one (Fig. 5a). The formation of these two limbs is due to a different role played by $\mathrm{Tb}$ and $\mathrm{Tf}$. In particular, the first limb is characterized by pairs of $\mathrm{Tb}$ and $\mathrm{Tf}$ whose sum is lower or equal to $15 \mathrm{~min}$. For such a case, by increasing $T_{\text {cycle }}$ a reduction of the cake layer thickness takes place since $\mathrm{Tb}$ has the main role on controlling the overall process. Specifically, by increasing Tf the cake layer tends to increase; however, such a trend is counterbalance by the $\mathrm{Tb}$ effect that tends to a reduced cake layer. Conversely, as soon as $T_{\text {cycle }}$ is higher than $15 \mathrm{~min}$, part of the cake layer is not removed by the backwashing and starts to build-up. Tb reaches an apparent maximum capacity to remove the cake layer. Therefore, an increase of $T_{\text {cycle }}$ essentially corresponds to an increase of $\mathrm{Tf}$ ( $\mathrm{Tb}$ remains equal to the maximum capacity—namely $5 \mathrm{~min}$ ) leading eventually to an increase of membrane resistance and permeate pumping energy requirement.

In Fig. 5b and c different profiles of the total resistances and cake thickness are reported for a value of $T_{\text {cycle }}$ equal to $11 \mathrm{~min}$ and for different values of $\mathrm{Tf}$ and $\mathrm{Tb}$. The increasing $\mathrm{Tf}$ and consequently reducing $\mathrm{Tb}$ ( $T_{\text {cycle }}$ is kept constant) leads to an increase of membrane resistance as well as of the cake thickness. Such a fact is consistent with the physical process. As discussed above, a reduction of $\mathrm{Tb}$ corresponds to a reduction of the efficiency of the backwashing and thus to an increase of the cake thickness.

In terms of money demand (namely, around $0.180 € \mathrm{~m}^{-3}$ ), a relevant influence of $\mathrm{Tb}$ and $\mathrm{Tf}$ was found; this is mainly due to the fact that the highest absolute money demanding contribution due to the energy requirement is represented by the cost of the power requirement for each blower that was maintained constant.

For scenario $3 \mathrm{EQI}$ decreases with the increase of $T_{\text {cycle }}$ takes place. This is mainly due to the fact that increasing $T_{\text {cycle }}$ the 
a
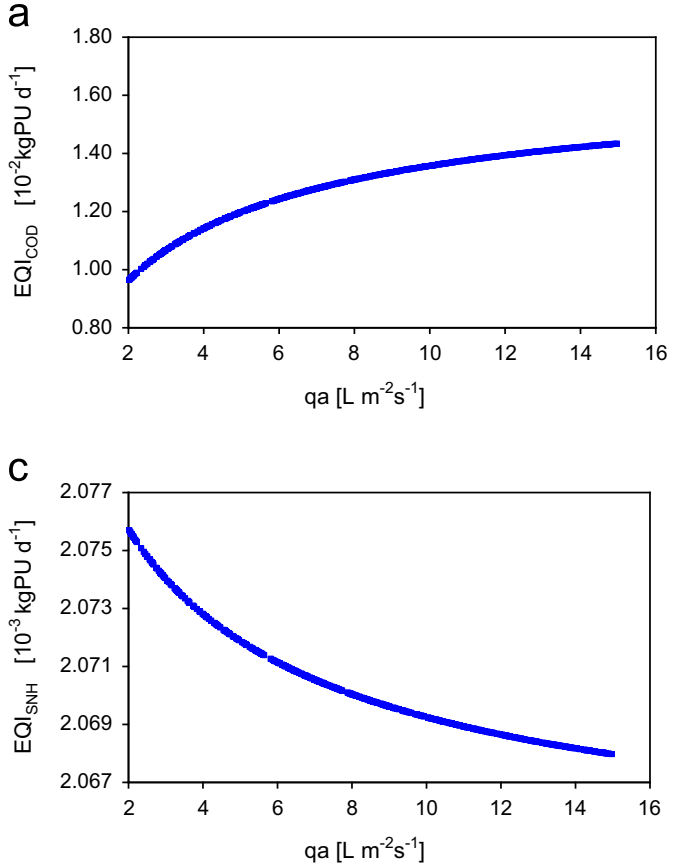

e

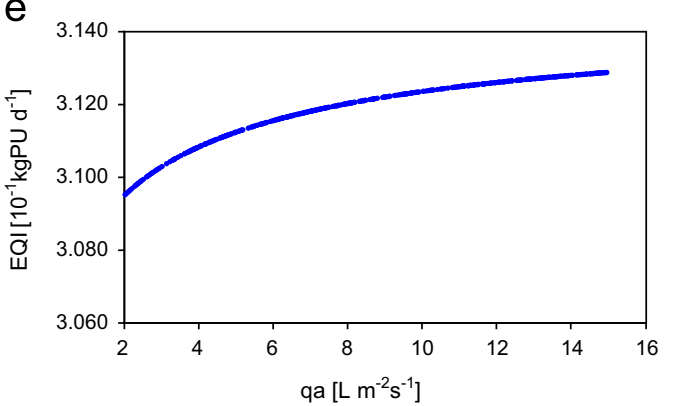

b

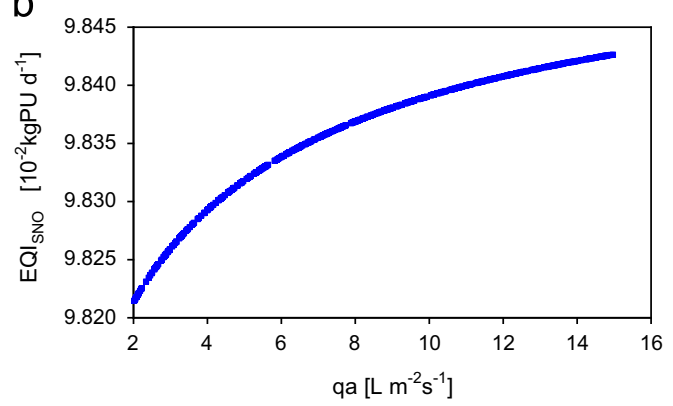

d

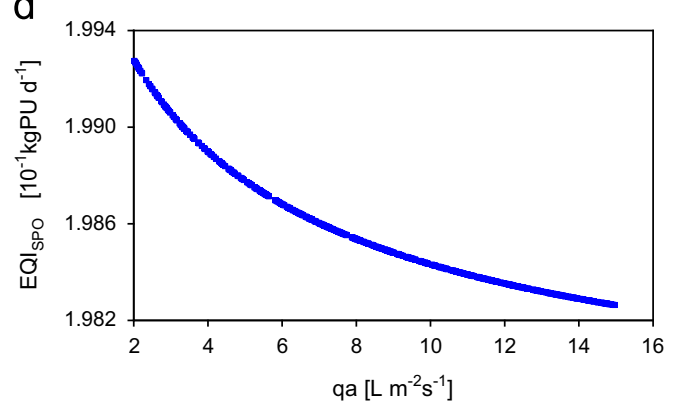

f

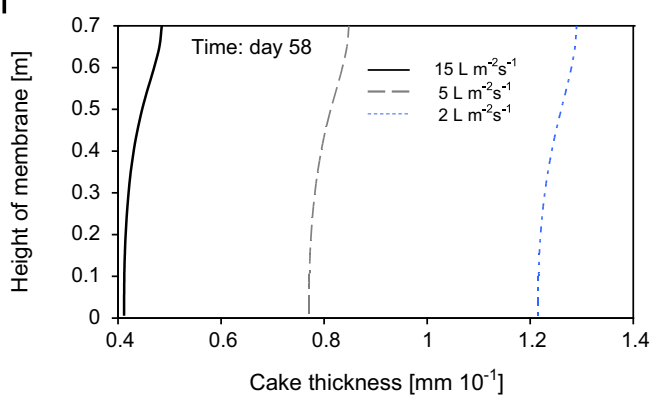

9

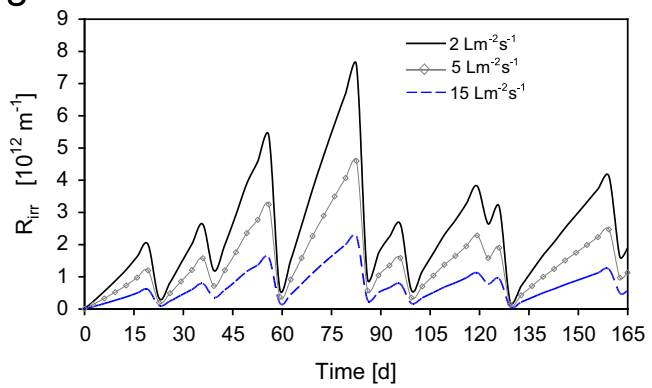

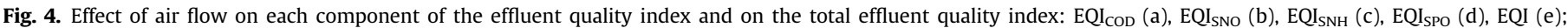

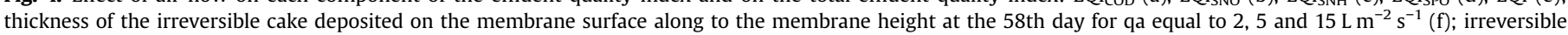
resistance $\left(R_{\text {irr }}\right)$ for qa equal to 2,5 and $15 \mathrm{~L} \mathrm{~m}^{-2} \mathrm{~s}^{-1}(\mathrm{~g})$ (scenario 2 ).

contribution of $\mathrm{Tf}$ increases and consequently the cake layer thickness is higher. As the cake layer is able to retain particles, by increasing the cake layer thickness the EQI decreases.

Finally, the best condition in terms of money demand corresponds to a value of $T_{\text {cycle }}$ around $88 \mathrm{~min}$ corresponding to $\mathrm{Tb}=1 \mathrm{~min}$ and $\mathrm{Tf}=87 \mathrm{~min}$. Such a result seems to be in contrast with the findings reported in Fig. 5a, where the minimum of $P_{\text {eff }}$ occurs for $T_{\text {cycle }}$ around $20 \mathrm{~min}$. However, the best condition in terms of money demand has been found on the basis of Eq. (6) where the term EF has an important role in case Tb and Tf are changed. For $\mathrm{Tb}=1 \mathrm{~min}$ and $\mathrm{Tf}=87 \mathrm{~min}$ the lowest $\mathrm{EF}$ occurs.

\subsection{Results of scenario 4}

Fig. 6 shows the results for scenario 4 in terms of variation of permeate pumping energy requirement and EQI versus qa. By analysing Fig. 6 it is evident that by increasing qa, the permeate pumping energy requirement decreases as an effect of the reduction of the cake layer thickness. However, it is evident that the influence of the variation of qa on $P_{\text {eff }}$ is lower with respect to scenario 2. Such a result is mainly due to the fact that the simultaneous variation of $\mathrm{Tb}$, Tf and qa conceals the effect of the single influence of qa. In terms of EQI no specific trend can be 

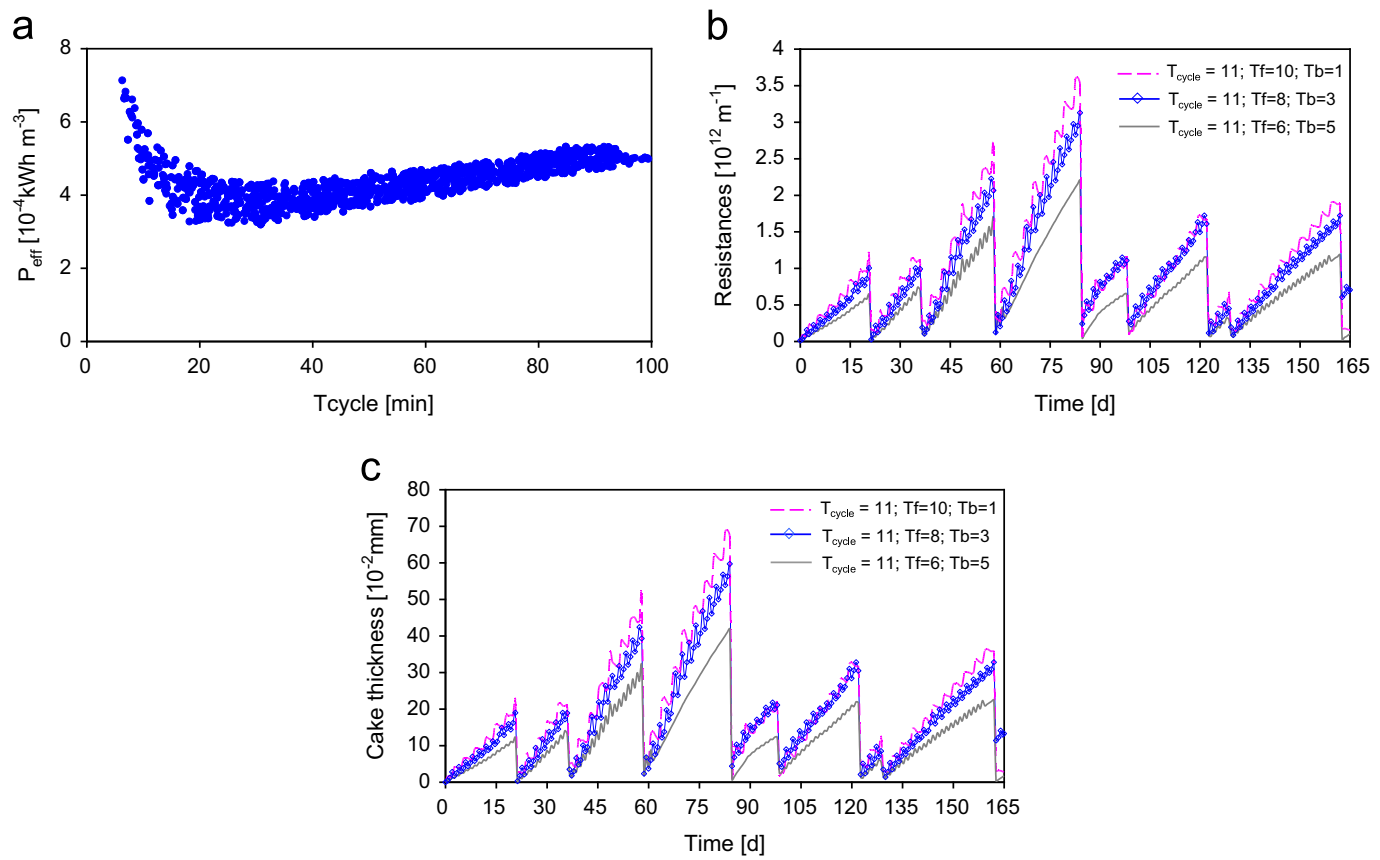

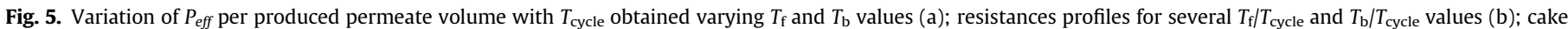

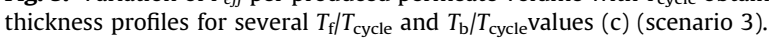
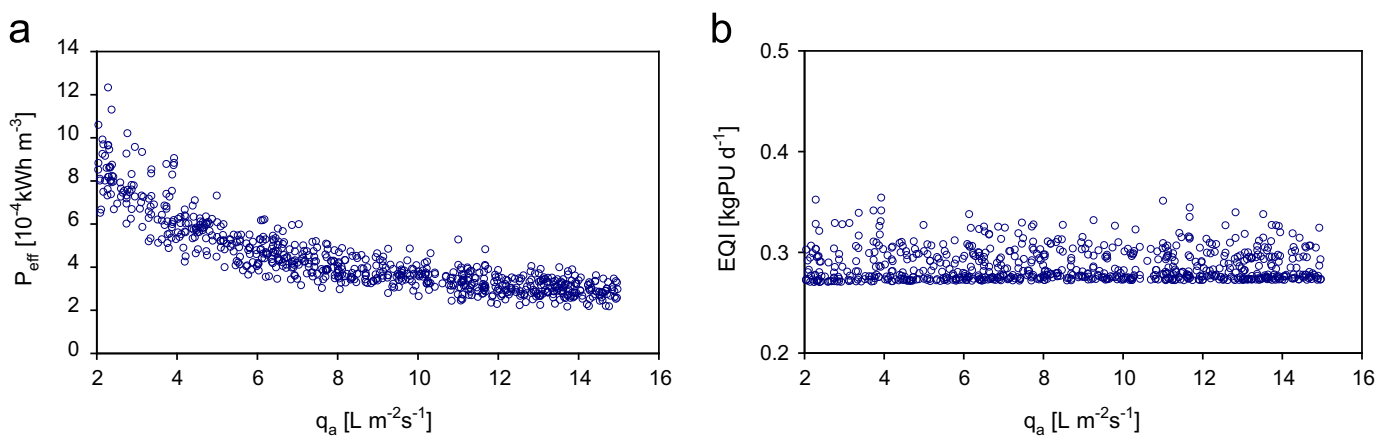

Fig. 6. Variation of $P_{e f f}$ with qa (a) and variation of and EQI with qa (b) (scenario 4).

found. Results reported on Fig. 6b show a high equifinality [46] of the variation of qa for EQI. Such a result is mainly due to the compensation effect caused by the simultaneous variation of qa, $\mathrm{Tb}$ and $\mathrm{Tf}$ thus demonstrate a high interaction between variables and stress the importance in considering a robust MBR modelling approach, such in the case of integrated models. An oversimplification of the modelling approach could lead to misleading results as an effect of the complexity of the involved processes and the high mutual interactions among the involved physical-chemical-biological processes.

In Fig. 7a the variation of $P_{\text {eff }}$ versus $T_{\text {cycle }}$ is reported. Fig. $7 \mathrm{~b}$ shows how EQI changes by varying $T_{\text {cycle }}$. By observing Fig. 7a one may conclude that a slight increase of $P_{\text {eff }}$ occurs by increasing the $T_{\text {cycle. }}$. However such a result, as discussed before, is deeply related to the different ratio $\mathrm{Tb} / T_{\text {cycle }}$ and $\mathrm{Tf} / T_{\text {cycle. }}$ The increase of $P_{\text {eff }}$ is mainly due to the high ratio of $\mathrm{Tf} / T_{\text {cycle }}$. Regarding $\mathrm{EQI}$, the variation with $T_{\text {cycle }}$ is lower than the case of scenario 3 where only $\mathrm{Tb}$ and $\mathrm{Tf}$ were changed. This is mainly due to an interaction effect caused by the simultaneous variation of qa, Tb and Tf. Even in this case the highest contribution of the money demand is due to qa. For scenario 4 the best condition in terms of energy demand and money demand occurs for qa around the minimum and $T_{\text {cycle }}$ around $57 \mathrm{~min}$ corresponding to $\mathrm{Tb}=1 \mathrm{~min}$ and $\mathrm{Tf}=56 \mathrm{~min}$.

\subsection{Results of scenario 5}

As discussed above, this scenario, different to the previous ones, is characterized by the activation of the membrane cleaning as a function of a TMP_TR, which is superimposed by the operator/ modeller. Globally the permeate pumping energy requirement is slightly higher than for the case of scenario 4, where no TMP_TR was superimposed (see Fig. 7a). Contrary to scenario 4, the obtained effect of qa on the permeate pumping energy requirement is less remarkable. Such results are an effect of membrane cleaning that is triggered by the achievement of TMP_TR. As an indirect effect, the air flow rate has a minor influence on the permeate pumping energy requirement respect to previous scenarios. Conversely, regarding $T_{\text {cycle, }}$ it has been found that by increasing $\mathrm{Tb}$ and $\mathrm{Tf}$ a reduction of the permeate pumping energy requirement takes place. Such a reduction is higher for low values of $T_{\text {cycle }}$ and tends to an asymptotic value of $P_{\text {eff }}$ for high value of $T_{\text {cycle. }}$. Such a result once again is due to the effect of the reduction of the cake layer discussed for scenario 3.

Fig. 8 shows the variation of the permeate pumping energy requirement vs the number of membrane cleanings. It is interesting to note that as far as $N_{\mathrm{c}}$ is lower than 18 , different values of the permeate pumping energy requirement are obtained 

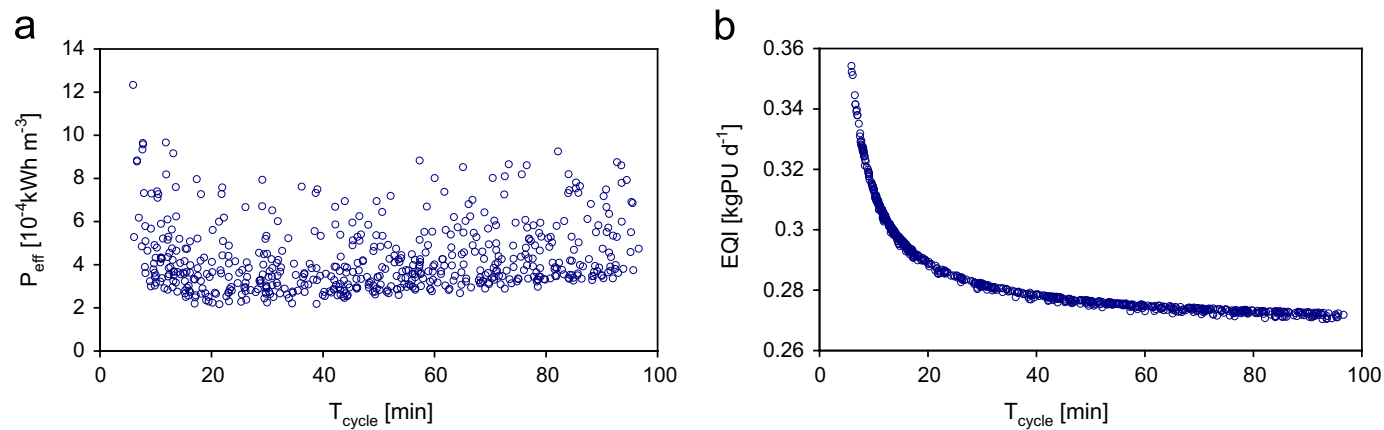

Fig. 7. Variation of the permeate pumping energy requirement with $T_{\text {cycle }}$ (a) and variation of EQI with $T_{\text {cycle }}$ (b) (scenario 4 ).

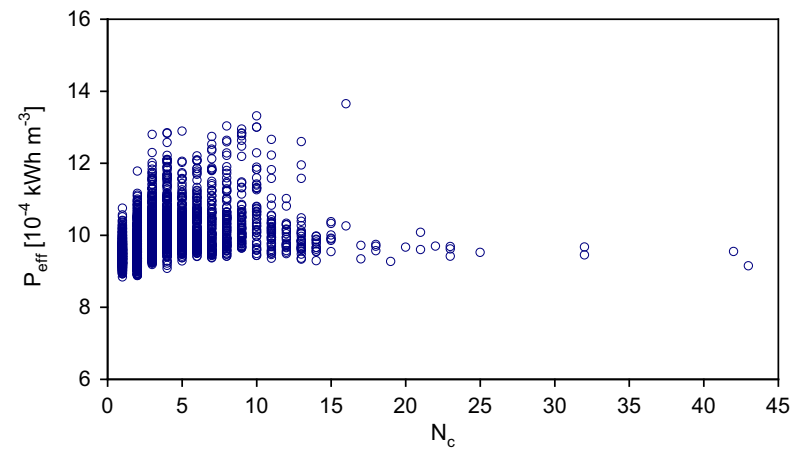

Fig. 8. Effect of the number of membrane cleaning on the permeate pumping energy requirement (scenario 5).

corresponding to a $N_{\mathrm{c}}$ value. Such a result is due to the combination of the different values of the operating variables (namely, qa, $\mathrm{Tb}$ and $\mathrm{Tf}$ ). In particular, for each $N_{\mathrm{c}}$ value lower than 18 , the highest value of the permeate pumping energy requirement corresponds to the lowest value of the air flow (higher cake layer thickness). As soon as $N_{\mathrm{c}}$ becomes higher than 18 , the range of the possible combinations of the operating variables (namely, qa, Tb and Tf) for a given value of $N_{\mathrm{c}}$ is narrower. For low values of $N_{\mathrm{c}}$, the cake layer thickness is high and the TMP_TR is rapidly achieved. Furthermore, for $N_{\mathrm{c}}>18$ the value of qa is approximately equal to the minimum value $\left(2 \mathrm{~L} \mathrm{~m}^{-2} \mathrm{~s}^{-1}\right)$ and the combinations of $\mathrm{Tb}$ and Tf (always grater than $60 \mathrm{~min}$ ) do not provide substantial variation to TMP. Therefore for scenario 5 two operating conditions can be employed for limiting the pumping energy costs: (i) lower $N_{c}$ values obtained by adopting a high air flow rate and (ii) higher $N_{c}$ values obtained employing a low air flow rate (i.e., $\mathrm{qa}=2 \mathrm{~L} \mathrm{~m}^{-2} \mathrm{~s}^{-1}$ ). However, it has to be stressed that the first case (lower $N_{\mathrm{c}}$ ) is characterized by higher OCs due to the high power requirements by the blowers.

In terms of EQI by varying both $T_{\text {cycle }}$ and qa no variation trend has been found. Such a result is likely due to the fact that the contribution of the cake layer effect is mainly regulated by the number of membrane cleanings. By increasing the number of membrane cleanings the variation of EQI (ranging from 0.27 and $0.35 \mathrm{~kg} \mathrm{PU} \mathrm{d}^{-1}$ minimum and maximum value, respectively) is reduced.

\subsection{Comparison between the scenarios}

In Table 5 a synthesis of the results for each scenario is reported. Specifically, for each scenario Table 5 reports the values of operating variables (namely, qa, Tb and Tf) which provided the minimum value for EQI, $P_{\text {eff }}$ and $P_{w}$. For each set of the operating variables, in the last two columns of Table 5 , the corresponding costs (namely, EF, OC and CC) are also reported.
For the benchmark scenario the EQI is equal to $0.310 \mathrm{~kg} \mathrm{PU} \mathrm{d}^{-1}$. The required energy in terms of $P_{w}$ and $P_{\text {eff }}$ per $\mathrm{m}^{3}$ of permeate produced is respectively equal to $0.5 \mathrm{~kW} \mathrm{~h} \mathrm{~m}^{-3}$ and $7.05 \times 10^{-4}$ $\mathrm{kW} \mathrm{h} \mathrm{m}^{-3}$ (Table 5).

Regarding scenario 2, the minimum value for the permeate pumping energy requirement corresponds to a qa value equal to $14.96 \mathrm{~L} \mathrm{~m}^{-2} \mathrm{~s}^{-1}$. Conversely, the lowest value for EQI and $P_{w}$ occurs with the lowest value of qa $\left(2.02 \mathrm{~L} \mathrm{~m}^{-2} \mathrm{~s}^{-1}\right)$. Such a result is consistent with the processes. By decreasing qa the value of the power requirement for each blower decreases (see, Eq. (7)). The EQI value related to the minimum of $P_{\text {eff }}$ is slightly higher than the value related to the minimum of $P_{\mathrm{w}}$ (see Table 5) causing the increase of the violation of the effluent limits as demonstrated by the higher value of EF. Moreover, the minimum value of $P_{\text {eff }}$ occurs corresponding to the maximum value of qa $\left(q a=14.96 \mathrm{~L} \mathrm{~m}^{-2} \mathrm{~s}^{-1}\right)$. This latter circumstance has determined the highest OC value for the scenario 2 that is $42 \%$ greater than the OC related to the minimum value of $P_{w}$. Thus, the substantial reduction in terms of energy demand related to qa equal to $2.02 \mathrm{~L} \mathrm{~m}^{-2} \mathrm{~s}^{-1}$ corresponding to the minimum value of $P_{w}$ and EQI, is the best solution for scenario 2 (Table 5). Although lower air flow operation leads to an increase of the OCs related to the energy requirement for permeate extraction (because the irreversible fouling increases due to the high SMP concentration) these are lower compared to the costs related to the air flow.

Regarding scenario 3, different results in terms of $\mathrm{Tb}$ and $\mathrm{Tf}$ have been obtained in optimizing EQI and $P_{\text {eff. }}$ Conversely, the same values of $\mathrm{Tb}$ and $\mathrm{Tf}$ were obtained for the minimum value of EQI and $P_{w}$. For scenario 3, the solution related to the minimum value of EQI and $P_{\mathrm{w}}$ (namely, $\mathrm{Tb}=5 \mathrm{~min}$ and $\mathrm{Tf}=50 \mathrm{~min}$ ) is the best solution in terms of operating costs. Even though there is a slight difference, both EF and OC resulted lower than the case of the minimum value of $P_{\text {eff }}$.

For scenario 4 different values of $\mathrm{Tf}, \mathrm{Tb}$ and qa have been found to correspond to the minimum value of EQI, $P_{\text {eff }}$ and $P_{w}$, respectively. As shown in Table 5 the minimum value of the permeate pumping energy requirement occurs at high value of qa $\left(13.70 \mathrm{~L} \mathrm{~m}^{-2} \mathrm{~s}^{-1}\right)$. This latter value of qa has substantially influenced the value of $O C$ that is higher with respect to the minimum related to the variables EQI and $P_{w}$. Despite the values of Tb and Tf related to the minimum values of the variables EQI and $P_{w}$ are quite different in terms of $\operatorname{Tf}$ ( 88 and $56 \mathrm{~min}$, respectively), more or less the same $\mathrm{OC}$ values have been obtained $(0.133$ and 0.132 $€ \mathrm{~m}^{-3}$, respectively). Such a result is mainly due to the fact that the minimum value of EQI and $P_{w}$ occurred almost at the same values of qa (i.e., 2.40 and $2.04 \mathrm{~L} \mathrm{~m}^{-2} \mathrm{~s}^{-1}$, respectively). Even for scenario 4 , the best solution for the plant operation is represented by the lowest value of qa $\left(2.02 \mathrm{~L} \mathrm{~m}^{-2} \mathrm{~s}^{-1}\right)$ corresponding to the minimum of $P_{w}$.

Finally, for scenario 5 the minimum values summarized in Table 5 shows (for EQI, $P_{w}$ and $P_{e f f}$ ) high value of Tf always greater 
Table 5

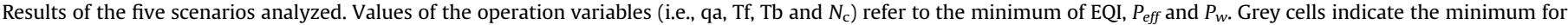
the corresponding operation variable. The last three columns contain respectively $E F, O C$ and $C C$ costs.

\begin{tabular}{|c|c|c|c|c|c|c|c|c|c|c|}
\hline & $\begin{array}{l}\text { qa } \\
{\left[\mathrm{L} \mathrm{m}^{-2} \mathrm{~s}^{-1}\right]}\end{array}$ & $\begin{array}{l}\text { Tf } \\
{[\mathrm{min}]}\end{array}$ & $\begin{array}{l}\mathrm{Tb} \\
{[\mathrm{min}]}\end{array}$ & $\begin{array}{l}N_{c} \\
{[-]}\end{array}$ & $\begin{array}{l}\text { EQI } \\
{\left[\mathrm{kg} \mathrm{PU} \mathrm{d}^{-1}\right]}\end{array}$ & $\begin{array}{l}P_{\text {eff }} \\
{\left[10^{-4} \mathrm{~kW} \mathrm{~h} \mathrm{~m}^{-3}\right]}\end{array}$ & $\begin{array}{l}P_{w} \\
{\left[\mathrm{~kW} \mathrm{~h} \mathrm{~m}^{-3}\right]}\end{array}$ & $\begin{array}{l}E F \\
{\left[€ \mathrm{~m}^{-3}\right]}\end{array}$ & $\begin{array}{l}O C \\
{\left[€ \mathrm{~m}^{-3}\right]}\end{array}$ & $\begin{array}{l}C C \\
{\left[10^{-2} \in \mathrm{m}^{-3}\right]}\end{array}$ \\
\hline Scenario 1 & 6.67 & 9 & 1 & 8 & 0.308 & 7.05 & 0.50 & 0.126 & 0.177 & 1.154 \\
\hline \multicolumn{11}{|c|}{ Benchmark scenario } \\
\hline \multirow[t]{2}{*}{ Scenario 2} & 2.02 & 9 & 1 & 8 & 0.310 & 14.00 & 0.15 & 0.11 & 0.132 & 1.154 \\
\hline & 14.96 & 9 & 1 & 8 & 0.313 & 4.30 & 1.10 & 0.135 & 0.234 & 1.154 \\
\hline \multirow[t]{2}{*}{ Scenario 3} & 6.67 & 50 & 5 & 8 & 0.271 & 4.21 & 0.50 & 0.123 & 0.174 & 1.154 \\
\hline & 6.67 & 21 & 10 & 8 & 0.281 & 3.20 & 0.51 & 0.135 & 0.187 & 1.154 \\
\hline \multirow[t]{3}{*}{ Scenario 4} & 2.40 & 88 & 4.5 & 8 & 0.270 & 8.74 & 0.17 & 0.109 & 0.133 & 1.154 \\
\hline & 13.70 & 12 & 9.4 & 8 & 0.288 & 2.16 & 1.06 & 0.135 & 0.231 & 1.154 \\
\hline & 2.04 & 56 & 1 & 8 & 0.273 & 8.82 & 0.15 & 0.11 & 0.132 & 1.154 \\
\hline \multirow[t]{3}{*}{ Scenario 5} & 9.20 & 89.2 & 9 & 3 & 0.270 & 9.70 & 0.69 & 0.106 & 0.166 & 0.436 \\
\hline & 11.53 & 87 & 9 & 2 & 0.271 & 8.89 & 0.86 & 0.108 & 0.180 & 0.290 \\
\hline & 2.02 & 61 & 1 & 16 & 0.272 & 10.25 & 0.15 & 0.105 & 0.140 & 2.306 \\
\hline
\end{tabular}

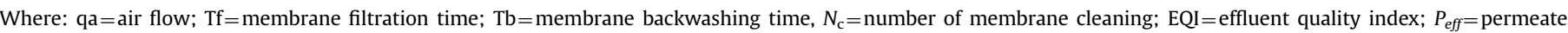
pumping energy requirement; $P_{\mathrm{w}}=$ power requirement for blower; $\mathrm{EF}=$ effluent fines; $\mathrm{OC}=$ total operational costs; $\mathrm{CC}=$ chemical consumption costs.

than 60 min. These results show that by imposing a maximum TMP for trigging membrane cleaning, a frequency reduction of backwashing takes place. Moreover, the superimposition of a maximum TMP leads to a drastic reduction of EQI (i.e., $0.270 \mathrm{~kg}$ $\left.\mathrm{PU} \mathrm{d}^{-1}\right)$ respect to scenario 1 and $2\left(0.308\right.$ and $0.313 \mathrm{~kg} \mathrm{PU} \mathrm{d}^{-1}$, respectively). In terms of both $\mathrm{OC}$ and $\mathrm{EF}$ the best plant operational condition corresponds to the lowest air flow rate (i.e., qa $=$ $2.02 \mathrm{~L} \mathrm{~m}^{-2} \mathrm{~s}^{-1}$ ). In particular for such a case although the number of membrane cleanings is double with respect to the other scenarios (namely, $N_{\mathrm{c}}=16$ ) the costs are the lowest. The CC value related to $\mathrm{qa}=2.02 \mathrm{~L} \mathrm{~m}^{-2} \mathrm{~s}^{-1}$ is equal to $2.306 \times 10^{-2} € \mathrm{~m}^{-3}$ and can be considered negligible compared to the OC. The OC value is mainly influenced by the cost for providing qa. The power requirement for blowers is the lowest one (namely, $0.15 \mathrm{~kW} \mathrm{~h} \mathrm{~m}^{-3}$ ) thus demonstrating the fact that the most important cost for an MBR plant is attributable to the air flow system.

Comparing the overall simulated scenarios, it comes out that scenario 2 and 4 provide the best economic solution in terms of $\mathrm{OC}$ (i.e., $0.132 € \mathrm{~m}^{-3}$ ). The operating conditions corresponding to scenario 2 and 4 with a qa around $2 \mathrm{~L} \mathrm{~m}^{-2} \mathrm{~s}^{-1}$ ) lead to an overall energy saving of $20 \%$ with respect to the benchmark scenario. Such energy reduction is also provided by scenario 5 considering a $\mathrm{qa}=2.02 \mathrm{~L} \mathrm{~m}^{-2} \mathrm{~s}^{-1}$ although it is slightly lower (namely, 19\% respect to benchmark scenario). The slight difference is due to the number of membrane cleanings that for scenario 5 is double with respect to the others. It has to be stressed that scenario 5 with a $\mathrm{qa}=2.02 \mathrm{~L} \mathrm{~m}^{-2} \mathrm{~s}^{-1}$ is also characterized by a thicker cake layer as demonstrated by the lower EQI and EF $\left(0.272 \mathrm{~kg} \mathrm{PU} \mathrm{d}^{-1}\right.$ and 0.105 , respectively) respect to scenario 2 and 4 with a qa around $2 \mathrm{~L} \mathrm{~m}^{-2} \mathrm{~s}^{-1}$. Such a fact is relevant: as recently demonstrated by Mannina and Di Bella [15], the thicker cake layer has a beneficial effect in terms of membrane protection towards fouling.

\section{Conclusions}

- MBR operation at low air flow showed a substantial reduction of the operating costs (20\% lower than the benchmark scenario costs) because the increase of the power required for the permeate extraction is negligible compared to the energy costs of the aeration system. Moreover at low air flow MBR was characterized by a good effluent quality as an effect of the high cake thickness.

- High air flow caused a reduction of the biological cake layer, which acts as an extra filter, leading to an increase of the EQI and of the operational costs in terms of EF. Therefore, despite the removal efficiency of MBRs can be quite high, in view of a costs saving strategy, operators have to pay attention on increasing air flow.

- The variation of qa influenced $R_{i r r}$, that represents the $90 \%$ of $R_{t}$, due to the lower/higher ability of the cake layer to retain SMPs.

- The increase of the duration of the backwashing and filtration respect to the manufacturer values (i.e., 1 and $9 \mathrm{~min}$, $\mathrm{Tb}$ and $\mathrm{Tf}$, respectively) do not provide any relevant influence on the money demand due to the low energy requirement for the permeate extraction/backwashing suggesting to revise the $\mathrm{Tb}$ and Tf values suggested by manufactures.

- Varying simultaneously the overall operational variables (i.e., qa, Tb and Tf) an high interaction was noticed. Such a result confirmed the relevant importance in considering integrated modeling approaches (i.e., modeling approaches which jointly takes into account both biological and physical processes) for MBR systems.

- Controlling membrane cleanings as a function of a maximum TMP value, it was derived that the lowest operational costs were corresponded to a number of membrane cleanings, which was double respect to the benchmark scenario thus suggesting, in view of operational costs saving, to operate MBRs without establishing a priori the membrane cleanings frequency.

- Further studies must be performed to also confirm experimentally the results, thus leading to a consolidation of the knowledge. Despite such a fact, the presented study can be considered as a leap forward for enhancing understanding on the different roles played by both physical and biological processes.

\section{References}

[1] S.J. Judd, C. Judd, Principles and Applications of Membrane Bioreactors in Water and Wastewater Treatmentsecond ed., Elsevier, London, UK, 2010.

[2] A. Drews, Membrane fouling in membrane bioreactors-characterisation, contradictions, cause and cures, J. Membr. Sci. 363 (1-2) (2010) 1-28.

[3] R. Dufresne, R.E. Lebrun, H.C. Lavallee, Comparative study on fluxes and performances during papermill wastewater treatment with membrane bioreactor, Can. J. Chem. Eng. 75 (1997) 95-103.

[4] B. Verrecht, S. Judd, G. Guglielmi, C. Brepols, J.W. Mulder, An aeration energy model for an immersed membrane bioreactor, Water Res. 42 (2008) 4761-4770.

[5] M.F.R. Zuthi, H.H. Ngo, W.S. Guo, Modelling bioprocesses and membrane fouling in membrane bioreactor (MBR): a review towards finding an integrated model, Bioresour. Technol. 122 (2012) 119-129.

[6] F. Meng, S.R Chae, A. Drews, M. Kraume, H.S. Shin, F. Yang, Recent advances in membrane bioreactors (MBRs): membrane fouling and membrane material, Water Res. 43 (2009) 1489-1512. 
[7] Z. Ahmed, J. Cho, B.R. Lim, K.G. Song, K.H. Ahn, Effects of sludge retention time on membrane fouling and microbial community structure in a membrane bioreactor, J. Membr. Sci. 287 (2007) 211-218.

[8] G. Guglielmi, D. Chiarani, D.P. Saroj, G. Andreottola, Sludge filterability and dewaterability in a membrane bioreactor for municipal wastewater treatment, Desalination 250 (2010) 660-665.

[9] P. Le-Clech, V. Chen, T.A.G. Fane, Fouling in membrane bioreactors used in wastewater treatment, J. Membr. Sci. 284 (1-2) (2006) 17-53.

[10] W. Lee, S. Kang, H. Shin, Sludge characteristics and their contribution to microfiltration in submerged membrane bioreactors, J. Membr. Sci. 216 (1-2) (2003) 217-227.

[11] S.S. Han, T.H. Bae, G.G. Jang, T.M. Tak, Influence of sludge retention time on membrane fouling and bioactivities in membrane bioreactor system, Process. Biochem. 40 (7) (2005) 2393-2400.

[12] F. Meng, F. Yang, B. Shi, H. Zhang, A comprehensive study on membrane fouling in submerged membrane bioreactors operated under different aeration intensities, Sep. Purif. Technol. 59 (2008) 91-100.

[13] J.S. Park, K.M. Yeon, C.H. Lee, Hydrodynamics and microbial physiology affecting performance of a new MBR, membrane-coupled high performance compact reactor, Desalination 172 (2005) 181-188.

[14] L. Ji, J. Zhou, Influence of aeration on microbial polymers and membrane fouling in submerged membrane bioreactors, J. Membr. Sci. 276 (2006) 168-177.

[15] G. Mannina, G. Di Bella, Comparing two start-up strategies for MBRs: experimental study and mathematical modelling, Biochem. Eng. J. 68 (2012) 91-103.

[16] A. Cosenza, G. Mannina, M.B. Neumann, G. Viviani, P.A. Vanrolleghem, Biological nitrogen and phosphorus removal in membrane bioreactors: model development and parameter estimation, Bioprocess. Biosyst. Eng. 36 (2013) 499-514.

[17] G. Mannina, G. Di Bella, G. Viviani, An integrated model for biological and physical process simulation in membrane bioreactors (MBRs), J. Membr. Sci $376(1-2)$ (2011) 56-69.

[18] A. Zarragoitia-González, S. Schetrite, M. Alliet, U. Jáuregui-Haza, C. Albasi, Modelling of submerged membrane bioreactor: conceptual study about link between activated sludge biokinetics, aeration and fouling process, J. Membr. Sci. 325 (2008) 612-624

[19] X. Flores-Alsina, I. Rodriguez-Roda, G. Sin, K.V. Gernaey, Multi-criteria evaluation of wastewater treatment plant control strategies under uncertainty, Water Res. (2008) 4485-4497.

[20] X. Flores-Alsina, A. Gallego, G. Feijoo, I. Rodriguez-Roda, Multiple-objective evaluation of wastewater treatment plant control alternatives, J. Environ. Manage. 91 (2010) 1193-1201.

[21] J. Guerrero, A. Guisasola, J. Comas, I. Rodriguez-Roda, J.A. Baeza, Multi-criteria selection of optimum WWTP control setpoints based on microbiology-related failures, effluent quality and operating costs, Chem. Eng. J. 188 (2012) 23-29.

[22] A. Fenu, G. Guglielmi, J. Jimenez, M. Spèrandio, D. Saroj, B. Lesjean, C. Brepols, C. Thoeye, I. Nopens, Activated sludge model (ASM) based modelling of membrane bioreactor (MBR) processes: a critical review with special regard to MBR specificities, Water Res. 44 (15) (2010) 4272-4294.

[23] T. Maere, B. Verrecht, S. Moerenhout, S. Judd, I. Nopens, BSM-MBR: a benchmark simulation model to compare control and operational strategies for membrane bioreactors, Water Res. 45 (2011) 2181-2190.

[24] J.B. Copp, The COST Simulation Benchmark Description and Simulator ManualOffice for official publications of the European Communities, Luxembourg, 2002.

[25] U. Jeppsson, M.N. Pons, The COST benchmark simulation model-current state and future perspective, Control Eng. Pract. 12 (3) (2004) 299-304.

[26] G. Ferrero, I. Rodríguez-Roda, J. Comas, Automatic control systems for submerged membrane bioreactors: a state-of-the-art, Water Res. 46 (11) (2012) 3421-3433.

[27] M.F.R. Zuthi, H.H. Ngo, W.S. Guo, L. Nghiem, F.I. Hai, A Mini, Review of biological phosphorus removal and its mathematical modelling for activated sludge and membrane bioreactor processes in wastewater treatment, Water Res. (2012), watres.2012.10.052 (accepted).

[28] A. Cosenza, G. Di Bella, G. Mannina, M. Torregrossa, G. Viviani, Biological nutrient removal and fouling phenomena in a University of Cape Town membrane bioreactor treating high nitrogen loads, J. Environ. Eng., 139, ASCE773-780.

[29] M. Henze, W. Gujer, T. Mino, M.C.M. van Loosdrecht, Activated sludge models ASM1, ASM2, ASM2d and ASM3, IWA Task Group on Mathematical Modelling for Design and Operation of Biological Wastewater treatmentIWA Publishing, London, UK, 2000.

[30] T. Jiang, S. Myngheer, D.J.W. De Pauw, H. Spanjers, I. Nopens, M.D. Kennedy, G. Amy, P.A. Vanrolleghem, Modelling the production and degradation of soluble microbial products (SMP) in membrane bioreactors (MBR), Water Res. 42 (20) (2008) 4955-4964.

[31] X. Li, X. Wang, Modelling of membrane fouling in a submerged membrane bioreactor, J. Membr. Sci. 278 (2006) 151-161.

[32] V.T. Kuberkar, R.H. Davis, Modeling of fouling reduction by secondary membranes, J. Membr Sci. 168 (2000) 243-257.

[33] G. Di Bella, G. Mannina, G. Viviani, An integrated model for physical-biological wastewater organic removal in a submerged membrane bioreactor: model development and parameter estimation, J. Membr. Sci. 322 (1) (2008) $1-12$
[34] J. Cho, K.G. Song, K.H. Ahn, The activated sludge and microbial substances influences on membrane fouling in submerged membrane bioreactor: unstirred batch cell test, Desalination 183 (2005) 425-429.

[35] J. Cho, K.G. Song, H. Yun, K.H. Ahn, J.Y. Kim, T.H. Chung, Quantitative analysis of biological effect on membrane fouling in submerged membrane bioreactor, Water Sci. Technol. 51 (2005) 9-18.

[36] APHA, AWWA, WEF, Standard Methods for the Examination of Water and Wastewater, 20th ed. American Public Health Association/American Water Works Association/Water Environment Federation, Washington, DC, USA 1998.

[37] D. Di Trapani, M. Capodici, A. Cosenza, G. Di Bella, G. Mannina, M. Torregrossa, G. Viviani, Evaluation of biomass activity and wastewater characterization in UCT-MBR pilot plant by means of respirometric techniques, Desalination 269 (2011) 190-197.

[38] U. Jeppsson, M.N. Pons, I. Nopens, J. Alex, J.B. Copp, K.V. Gernaey, C. Rosen J.P. Steyer, P.A. Vanrolleghem, Benchmark simulation model no 2: genera protocol and exploratory case studies, Water Sci. Technol. 56 (8) (2007) 67-78.

[39] P.A. Vanrolleghem, S. Gillot, Robustness and economic measures as control benchmark performance criteria, Water Sci. Technol. 45 (4-5) (2002) 117-126.

[40] P.A. Vanrolleghem, U. Jeppsson, J. Carstensen, B. Carlsson, G. Olsson, Integration of wastewater treatment plant design and operation-a systematic approach using cost functions, Water Sci. Technol. 34 (3-4) (1996) 159-171.

[41] C. Brepols, MBR Practice Report: Operating Large Scale Membrane Bioreactors for Municipal Wastewater Treatment, IWA Publishing, 2010.

[42] M.L. Davis, Water and Wastewater Engineering: Design Principles and PracticeMcGraw-Hill, New York, 2010.

[43] A. Stare, D. Vrecko, N. Hvala, S. Strmcnik, Comparison of control strategies for nitrogen removal in an activated sludge process in terms of operating costs, Water Res 41 (9) (2007) 2004-2014.

[44] G. Mannina, G. Di Bella, G. Viviani, Uncertainty assessment of a membrane bioreactor model using the GLUE methodology, Biochem. Eng. J. 52 (2) (2010) 263-275.

45] A. Saltelli, Sensitivity Analysis. John Wiley \& Sons, Chichester, 2000.

46] K.J. Beven, A.M. Binley, The future of distributed models model calibration and uncertainty prediction, Hydrol. Processes 6 (3) (1992) 279-298.

47] G. Mannina, A. Cosenza, P.A. Vanrolleghem, G. Viviani, A practical protocol for calibration of nutrient removal wastewater treatment models, J. Hydroinf. 13 (4) (2011) 575-595.

[48] G. Mannina, G. Viviani, Hybrid moving bed biofilm reactors: an effective solution for upgrading a large wastewater treatment plant, Water Sci. Technol. 60 (5) (2009) 1103-1116

[49] G. Mannina, G. Viviani, Separate and combined sewer systems: a long-term modelling approach, Water Sci. Technol. 60 (3) (2009) 555-565.

[50] G. Freni, G. Mannina, Bayesian approach for uncertainty quantification in water quality modelling: the influence of prior distribution, J. Hydrol. 392 (2010) 31-39.

[51] A. Saltelli, S. Tarantola, F. Campolongo, M. Ratto, Sensitivity Analysis in Practice. A Guide to Assessing Scientific Models. John Wiley \& Sons Publishers, 2004.

52] C.B.S. Dotto, G. Mannina, M. Kleidorfer, L. Vezzaro, M. Henrichs, D.T. McCarthy, G. Freni, W. Rauch, A. Deletic, Comparison of different uncertainty techniques in urban stormwater quantity and quality modelling, Water Res. 46 (8) (2012) 2545-2558.

[53] G. Mannina, G. Viviani, An urban drainage stormwater quality model: model development and uncertainty quantification, J. Hydrol. 381 (3-4) (2010) 248-265.

[54] S. Arabi, G. Nakhla, Characterization of foulants in conventional and simultaneous nitrification and denitrification membrane bioreactors, Sep. Purif. Technol. 29 (2009) 153-160.

[55] M. Sarioglu, G. Insel, D. Orhon, Dynamic in-series resistance modelling and analysis of submerged membrane bioreactor using a novel filtration mode, Desalination (2012) 285-294.

[56] C. Suh, S. Lee, J. Cho, Investigation of the effects of membrane fouling control strategies with integrated membrane bioreactor model, J. Membr. Sci 429 (15) (2013) 268-281.

[57] B. Verrecht, T. Maere, I. Nopens, C. Brepols, S. Judd, The cost of a large-scale hollow fibre MBR, Water Res. 44 (18) (2010) 5274-5283.

[58] T. Wintgens, J. Rosen, T. Melin, C. Brepols, K. Drensla, N. Engelhardt, Modelling of a membrane bioreactor system for municipal wastewater treatment, J. Membr. Sci 216 (2003) 55-65.

[59] S.G. Lu, T. Imai, M. Ukita, M. Sekine, T. Higuchi, M. Fukagawa, A model for membrane bioreactor process based on the concept of formation and degradation of soluble microbial products, Water Res 35 (2000) 2038-2048.

[60] M.F.R. Zuthi, H.H. Ngo, W.S. Guo, J. Zhang, S. Liang, A review towards finding a simplified approach for modelling the kinetics of the soluble microbia products (SMP) in an integrated mathematical model of membrane bioreactor (MBR), Int. Biodeterior. Biodegrad. (2013).

61] I Nopens, L Benedetti, U Jeppsson, M-N Pons, J Alex, J.B. Copp, K V Gernaey, C Rosen, J-P Steyer, P A Vanrolleghem, Benchmark simulation model no 2 finalisation of plant layout and default control strategy, Water Sci. Technol. 62 (9) (2010) 1967-1974.

[62] Montserrat Dalmaua, Ignasi Rodriguez-Rodaa, E. Ayesa, J. Odriozola, L. Sancho, J. Comas, Development of a decision tree for the integrated operation of nutrient removal MBRs based on simulation studies and expert knowledge, Chem. Eng. J. 217 (2013) 174-184. 